\title{
НЕЛИНЕЙНЫЕ ЭФФЕКТЫ СОВМЕСТНОГО ВОЗДЕЙСТВИЯ ОКСИДОВ $p$ - И $d$-ЭЛЕМЕНТОВ ПРИ СОЗДАНИИ ТОНКИХ ПЛЕНОК НА ПОВЕРХНОСТИ GaAs И InP ОБЗОР
}

\author{
(C) 2018 В. Ф. Кострюков, И. Я. Миттова, Е. В. Томина, Б. В. Сладкопевцев, \\ А. С. Паршина, Д. С. Балашева \\ Воронежский государственный университет, Университетская пл., 1, 394018 Воронеж, Россия \\ e-mail:vc@chem.vsu.ru
}

Поступила в редакцию 03.09.2018

\begin{abstract}
Аннотация. Рассмотрен процесс термооксидирования арсенида галлия и фосфида индия под воздействием бинарных оксидных композиций (хемостимулятор+хемостимулятор и хемостимулятор+инертный компонент). Установлены и интерпретированы нелинейные эффекты зависимости толщины оксидной пленки на поверхности GaAs и InP от состава композиции оксидов-хемостиуляторов. Доказана возможность получения аддитивной во всем интервале составов зависимости толщины оксидной пленки на поверхности GaAs от состава при использовании композиций оксид-хемостимулятор+инертный компонент. Установлена пространственная локализация связывающих взаимодействий между оксидами-хемостимуляторами, которые приводят к наблюдаемым нелинейным эффектам. Синтезированные таким способом тонкие пленки на поверхности GaAs и InP обладают улучшенными электрофизическими свойствами и проявляют газочувствительный отклик в атмосфере газов-восстановителей.
\end{abstract}

Ключевые слова: арсенид галлия, фосфид индия, термооксидирование, хемостимулятор, наноразмерные плёнки, нелинейные эффекты, гетероструктуры, газочувствительность.

DOI: https://doi.org/10.17308/kcmf.2018.20/625

\section{ВВЕДЕНИЕ}

Многочисленные работы [1-9] показали эффективность применения индивидуальных оксидов $p$ - и $d$-элементов как хемостимуляторов процессов термооксидирования GaAs и InP, независимо от способа их введения в окислительную среду. Установленные при этом закономерности обобщены в работах $[10,11]$.

Принципиально иным подходом является случай термооксидирования полупроводника при одновременном воздействии двух хемостимуляторов (композиция оксидов переменного состава). Если в системе одновременно присутствуют два соединения-хемостимулятора, то реакции с их участием могут осуществляться двумя различными способами: 1) параллельно и независимо; 2) оказывая взаимное влияние друг на друга (рис. 1).

В случае $(a)$ взаимодействие между соединениями-хемостимуляторами отсутствует, и процессы, протекающие в единой системе, являются независимыми. Общая скорость процесса накопления це- левого продукта будет определяться суммой скоростей двух отдельных процессов, то есть процессы параллельны. В варианте $(b)$ наблюдается дополнительное взаимовлияние реагентов, приводящее к тому, что общая скорость процесса не будет равняться сумме скоростей двух отдельных процессов,

$$
\begin{aligned}
& A+B \Rightarrow D+E, V_{1} \quad A+B \Rightarrow D+E, V_{1} \\
& V_{\text {оби }}=V_{1}+V_{2} \quad B \cdot C \Leftarrow \uparrow V_{\text {оби }} \neq V_{1}+V_{2} \\
& A+C \Rightarrow D+F, V_{2} \quad A+C \Rightarrow D+F, V_{2}
\end{aligned}
$$

$a$

$b$

$A$ - полупроводниковая подложка, $B$ и $C$ - соединения-хемостимуляторы, $D, E, F$ - продукты взаимодействия полупроводника с хемостимуляторами Рис. 1. Схема возможных вариантов воздействия двух соединений-хемостимуляторов в единой композиции на процесс термооксидирования полупроводника

[Fig. 1. Scheme of possible variants of the effect of two compounds-chemostimulators in a single composition on the process of semiconductor thermal oxidation] 
а будет либо больше, либо меньше ее в зависимости от характера взаимодействия хемостимуляторов. Тогда эти реакции уже не будут независимыми и параллельными. В первом случае $(a)$ должна реализовываться аддитивная зависимость толщины оксидного слоя на поверхности полупроводника от состава композиции, обусловленная действием каждого хемостимуляторов с учетом его содержания в композиции. Во втором случае $(b)$ зависимость толщины оксидного слоя на поверхности полупроводника от состава композиции уже не будет аддитивной, а будут наблюдаться отклонения от аддитивности либо в положительную, либо в отрицательную сторону в зависимости от характера связывающей стадии.

При воздействии композиций оксидов-хемостимуляторов на процесс термооксидирования полупроводников возможны следующие варианты их взаимного влияния друг на друга и на полупроводниковую подложку (рис. 2).

Стрелки на рис. 2 символизируют влияние оксида, входящего в состав композиции, на полупроводниковую подложку или взаимодействие между хемостимуляторами, которое в самом общем случае может иметь место как непосредственно в твердой фазе, так и в газовой и на поверхности полупроводника. В случае (a) имеем систему с двумя оксидами, каждый из которых не только индивидуально оказывает хемостимулирующее воздействие на процесс термооксидирования полупроводника, но и влияет на другой оксид, входящий в состав композиции. В варианте $(b)$ два не взаимодействующих между собой оксида по отдельности оказывают влияние на процесс термооксидирования полупроводника. Ситуация (c) предполагает два оксида, вступающих в химическую реакцию, но только один из них оказывает хемостимулирующее действие на рост оксидной пленки. Случай (e) отвечает двум взаимодействующим оксидам, ни один из которых не способен взаимодействовать с подложкой. Вариант $(d)$ означает наличие двух оксидов, инертных друг к другу, один из которых является хемостимулятором, а второй нет.

Для $(a)$ и $(c)$ возможны нелинейные эффекты зависимости толщины оксидного слоя на поверхности полупроводника от состава композиции. В случаях $(b)$ и $(d)$ можно ожидать аддитивной зависимости толщины от состава композиции активаторов. Вариант (e) не представляет практического интереса, поскольку отсутствует само явление хемостимулирования.
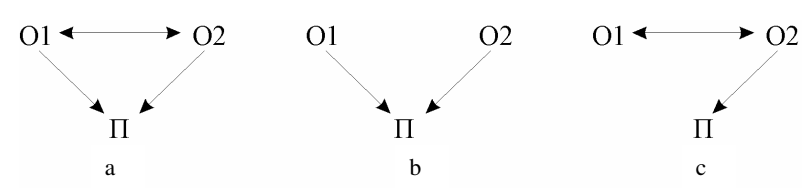

O1
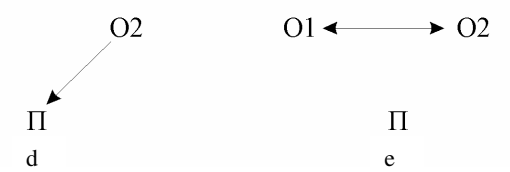

Рис. 2. Варианты взаимоотношений между компонентами композиции хемостимуляторов и полупроводниковой подложкой (O1 и О2 - оксиды-хемостимуляторы, П - полупроводниковая подложка)

[Fig . 2. Options for the relationship between the components of the composition of chemostimulators and the semiconductor (O1 and $\mathrm{O} 2$ - oxide-chemostimulators, $\mathrm{P}$ semiconductor)]

\section{ТЕРМООКСИДИРОВАНИЕ GaAs ПРИ СОВМЕСТНОМ ВОЗДЕЙСТВИИ ОКСИДОВ $p$ - И $d$-ЭЛЕМЕНТОВ ИЗ ЕДИНОЙ КОМПОЗИЦИИ}

В работах [12-18] рассмотрено хемостимулирующее действие композиций оксидов р-элементов $\left(\mathrm{Sb}_{2} \mathrm{O}_{3}, \mathrm{Bi}_{2} \mathrm{O}_{3}, \mathrm{PbO}\right)$ на процесс термооксидирования GaAs. Хемостимуляторы вводили в систему через газовую фазу испарением из контейнера, крышкой которого служила пластина GaAs. Такой вариант относится к способу 1 введения хемостимулятора в систему согласно классификации, приведенной в [11].

Для представления зависимости толщины оксидной пленки на GaAs от состава композиции хемостимуляторов предложено использовать модифицированные диаграммы типа “состав - свойство”, в которых по оси ординат представлено не некоторое физическое свойство системы, а кинетическая характеристика - толщина оксидной пленки, достигаемая к определенному моменту времени. Ось абсцисс является осью составов композиции.

Для количественной интерпретации полученных результатов в рассмотрение была введена относительная интегральная толщина, которая представляет собой разность между фактически достигаемой к данному моменту времени толщиной оксидной пленки и ожидаемой в предположении линейно независимых параллельных вкладов за счет индивидуального действия оксидов-хемостимуляторов, рассчитываемых по правилу аддитивности:

$$
d^{R}(x, \tau)=d(x, \tau)-\sum x_{i} \cdot d_{i}^{0}(\tau),
$$


где $d(x, \tau)$ - экспериментальная толщина оксидной пленки на поверхности GaAs, $d_{i}^{0}(x, \tau)$ - толщины, обусловленные независимым действием индивидуальных оксидов- хемостимуляторов; $x_{i}$ - мольные доли хемостимуляторов в композиции [12].

Полученные таким образом зависимости представлены на рис. 3 (толщина оксидной пленки) и 4 (относительная интегральная толщина).
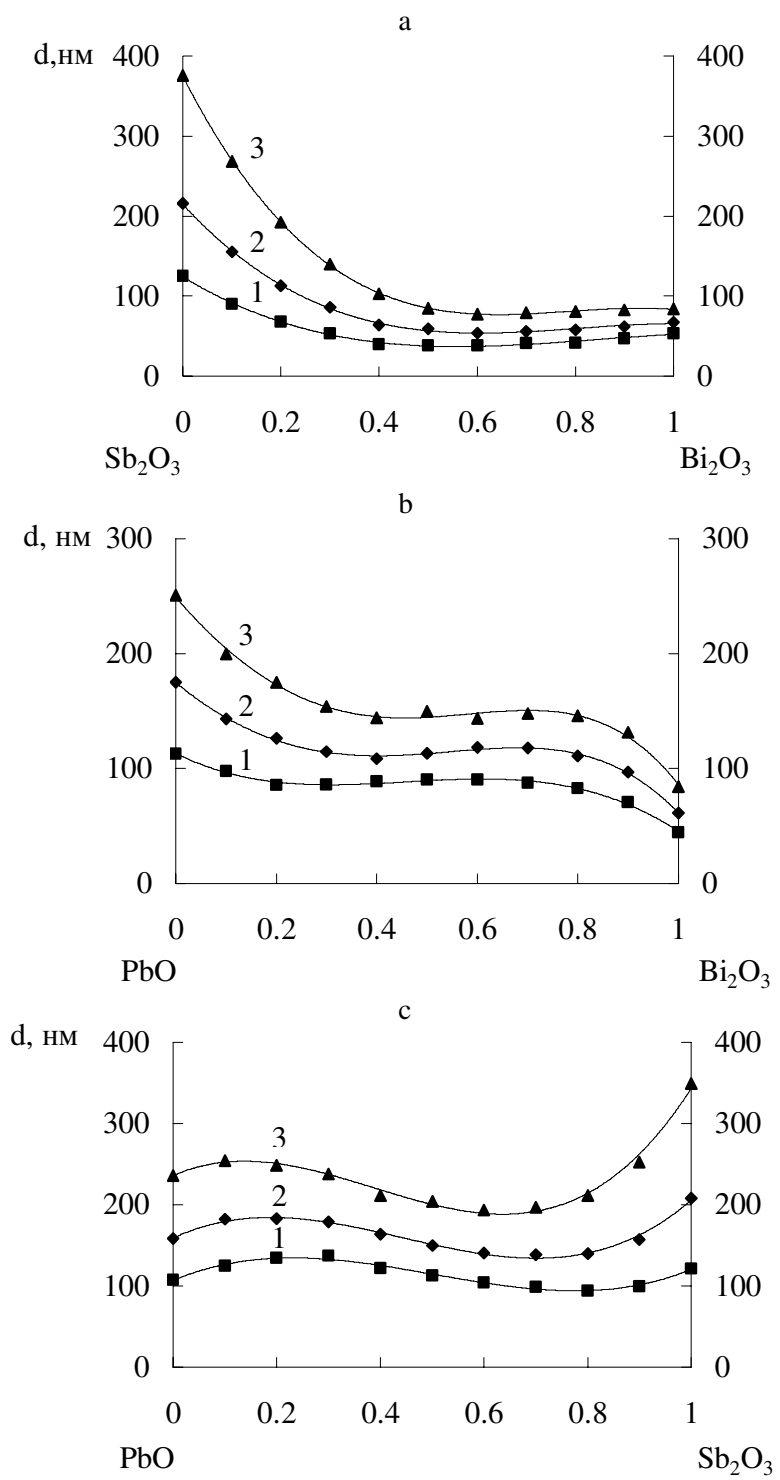

Рис. 3. Зависимости толщины оксидной пленки на GaAs от состава композиции оксидов-хемостимуляторов при $530{ }^{\circ} \mathrm{C}$ для: $a-\mathrm{Sb}_{2} \mathrm{O}_{3}+\mathrm{Bi}_{2} \mathrm{O}_{3} ; b-\mathrm{PbO}+\mathrm{Bi}_{2} \mathrm{O}_{3} ; c$ $-\mathrm{PbO}+\mathrm{Sb}_{2} \mathrm{O}_{3}$ при различных временах оксидирования:

$$
1 \text { - } 10 \text { мин; 2-20 мин; 3-40 мин }
$$

[Fig. 3. Dependence of the thickness of the oxide film on GaAs from the composition of oxides of chemostimulators at $530{ }^{\circ} \mathrm{C}$ for: $a-\mathrm{Sb}_{2} \mathrm{O}_{3}+\mathrm{Bi}_{2} \mathrm{O}_{3} ; b-\mathrm{PbO}+\mathrm{Bi}_{2} \mathrm{O}_{3} ; c-$ $\mathrm{PbO}+\mathrm{Sb}_{2} \mathrm{O}_{3}$ at different times of oxidation: $1-10 \mathrm{~min} ; 2$ $-20 \mathrm{~min} ; 3-40 \mathrm{~min}$ ]
При термооксидировании GaAs под воздействием композиции $\mathrm{Sb}_{2} \mathrm{O}_{3}+\mathrm{Bi}_{2} \mathrm{O}_{3}$ во всем интервале составов отклонение от аддитивности отрицательно. В процессах под воздействием композиций с участием $\mathrm{PbO}$ отклонение от аддитивности является знакопеременным, но его характер различен в зависимости от природы второго вводимого компонента.
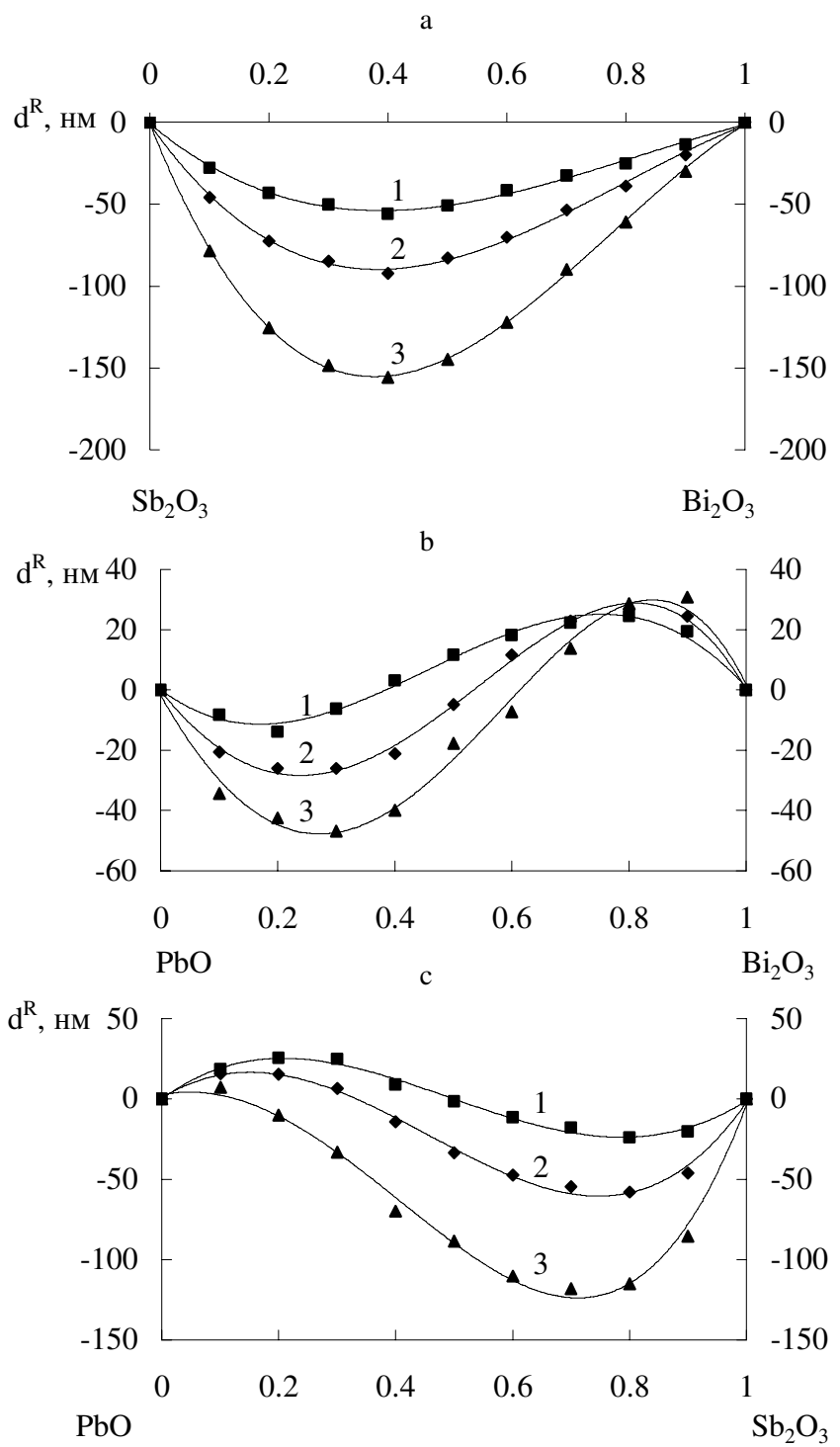

Рис. 4. Концентрационные зависимости относительной интегральной толщины оксидной пленки на GaAs при $530{ }^{\circ} \mathrm{C}: 1-10$ мин; $2-20$ мин; $3-40$ мин для композиций: $a-\mathrm{Sb}_{2} \mathrm{O}_{3}+\mathrm{Bi}_{2} \mathrm{O}_{3} ; b-\mathrm{PbO}+\mathrm{Bi}_{2} \mathrm{O}_{3} ; c-$ $\mathrm{PbO}+\mathrm{Sb}_{2} \mathrm{O}_{3}$

[Fig. 4. Concentration dependence of the relative integral thickness of the oxide film on $\mathrm{GaAs}$ at $530^{\circ} \mathrm{C}: 1-10$ $\min ; 2-20 \mathrm{~min} ; 3-40 \mathrm{~min}$. for the compositions: $a-$

$$
\left.\mathrm{Sb}_{2} \mathrm{O}_{3}+\mathrm{Bi}_{2} \mathrm{O}_{3} ; b-\mathrm{PbO}+\mathrm{Bi}_{2} \mathrm{O}_{3} ; c-\mathrm{PbO}+\mathrm{Sb}_{2} \mathrm{O}_{3}\right]
$$


Добавление $\mathrm{Bi}_{2} \mathrm{O}_{3}$ к $\mathrm{PbO}$ тормозит его хемостимулирующее действие (как и для композиции $\mathrm{Sb}_{2} \mathrm{O}_{3}+\mathrm{Bi}_{2} \mathrm{O}_{3}$ ), но добавление $\mathrm{PbO}$ к $\mathrm{Bi}_{2} \mathrm{O}_{3}$, напротив, увеличивает эффективность действия последнего. Для $\mathrm{PbO}+\mathrm{Sb}_{2} \mathrm{O}_{3}$ характер взаимовлияния оксидов-хемостимуляторов на оксидирование GaAs противоположен: добавление $\mathrm{Sb}_{2} \mathrm{O}_{3}$ приводит к неаддитивному возрастанию толщины оксидной пленки, в то время как добавление $\mathrm{PbO}$ к $\mathrm{Sb}_{2} \mathrm{O}_{3}-$ к неаддитивному уменьшению. Нелинейные эффекты закономерно развиваются с увеличением времени процесса. При термооксидировании $\mathrm{GaAs}$ под воздействием композиций $\mathrm{Sb}_{2} \mathrm{O}_{3}+\mathrm{Bi}_{2} \mathrm{O}_{3}$ отрицательное отклонение увеличивается по абсолютной величине, причем минимум практически не смещается по оси состава, оставаясь на уровне $\sim 40$ мол. $\% \mathrm{Bi}_{2} \mathrm{O}_{3}$ (рис. 4).

Для процессов на GaAs под воздействием композиций с участием $\mathrm{PbO}$ имеет место общая закономерность - расширение по составу и увеличение по абсолютной величине области отрицательного отклонения от аддитивности с ростом времени оксидирования. Особенности же изменения положительного отклонения различны по характеру. Для « $\mathrm{PbO}+\mathrm{Sb}_{2} \mathrm{O}_{3} »-$-процесса с ростом температуры отклонение от аддитивности уменьшается как по абсолютной величине, так и по интервалу составов. $\mathrm{B} « \mathrm{PbO}+\mathrm{Bi}_{2} \mathrm{O}_{3} »$-процессе отклонение от аддитивности в этом направлении уменьшается только по интервалу составов, а абсолютная величина максимума положительного отклонения возрастает.

На основании данных ультрамягкой рентгеновской эмиссионной спектроскопии (УМРЭС) и ИКспектроскопии сделан вывод, что основной компонент в пленках - галлий. В заметных количествах (в среднем около 10 ат. \%) присутствует мышьяк. В пленках, полученных под воздействием композиций, содержащих $\mathrm{PbO}$, обнаружен свинец ( 1$2 \%)$, причем его содержание в пленке закономерно падает с уменьшением содержания в композициях как с $\mathrm{Sb}_{2} \mathrm{O}_{3}$, так и с $\mathrm{Bi}_{2} \mathrm{O}_{3}$. Все компоненты пленок находятся в окисленном состоянии, о чем свидетельствуют пики поглощения, отвечающие связям их с кислородом.

Согласно данным рентгенофазового анализа (РФА) основными компонентами в используемых бинарных композициях хемостимуляторов являются первоначально вводимые оксиды, причем при отжиге происходит превращение $\mathrm{Sb}_{2} \mathrm{O}_{3}$ в $\mathrm{Sb}_{2} \mathrm{O}_{4}$. Однако во всех случаях, кроме набора линий, характерных для этих хемостимуляторов, имеются менее ярко выраженные пики, со- ответствующие образованию новых промежуточных фаз.

Таким образом, воздействие на процесс термооксидирования GaAs рассмотренных выше композиций не является аддитивным и параллельным. Наличие отклонений от аддитивной зависимости толщины оксидной пленки на поверхности GaAs от состава композиции оксидов-хемостимуляторов говорит о наличии между ними взаимного влияния и позволяет отнести рассмотренные системы к варианту $(a)$ схемы, приведенной на рис. 2.

В работах $[19,20]$ рассмотрено воздействие композиций $\mathrm{CrO}_{3}+\mathrm{PbO}$ и $\mathrm{CrO}_{3}+\mathrm{V}_{2} \mathrm{O}_{5}$ на процесс термооксидирования GaAs. Оксид хрома (VI) является активным хемостимулятором [21] и ускорение процесса оксидирования GaAs в этом случае обусловлено цепочкой последовательных превращений $\mathrm{CrO}_{3} \rightarrow \mathrm{Cr}_{3} \mathrm{O}_{8} \rightarrow \mathrm{Cr}_{2} \mathrm{O}_{5} \rightarrow\left(\mathrm{CrO}_{2}\right) \rightarrow \mathrm{Cr}_{2} \mathrm{O}_{3}$. Выбранные в работах $[19,20]$ вторые оксиды-хемостимуляторы $\left(\mathrm{PbO}\right.$ и $\left.\mathrm{V}_{2} \mathrm{O}_{5}\right)$ должны оказывать целенаправленное воздействие на процесс последовательного термолиза $\mathrm{CrO}_{3}$ - более основный $\mathrm{PbO}$ будет взаимодействовать с $\mathrm{CrO}_{3}$, а более кислотный $\mathrm{V}_{2} \mathrm{O}_{5}-\mathrm{c} \mathrm{Cr}_{2} \mathrm{O}_{3}$. Поэтому в данных системах авторами ожидалась более ярко выраженная нелинейность зависимости толщины оксидного слоя на поверхности GaAs от состава композиции хемостимуляторов.

На рис. 5 приведены графические зависимости толщины и относительной интегральной толщины оксидной пленки на GaAs от состава композиций $\mathrm{CrO}_{3}+\mathrm{PbO}$, полученные при $500{ }^{\circ} \mathrm{C}$. Небольшая добавка $\mathrm{PbO}$ приводит к некоторому торможению разложения исходного активатора $\mathrm{CrO}_{3}$ до продуктов (данные РФА), которые являются менее активными с точки зрения активирующего действия, чем непосредственно $\mathrm{CrO}_{3}$. То есть, при данном соотношении компонентов композиции $\mathrm{PbO}$ замедляет разложение $\mathrm{CrO}_{3}$, поэтому последний, в течение длительного периода находясь в системе в исходном состоянии, обеспечивает наибольшее ускорение формирования слоев.

РФА композиций $\mathrm{CrO}_{3}+\mathrm{PbO}$ показал наличие не только продуктов превращения $\mathrm{CrO}_{3}$ и $\mathrm{PbO}$, но и фаз $\mathrm{Pb}_{2} \mathrm{O}_{3}$ и $\mathrm{PbO}_{2}$. Образование новых оксидов свинца в составе хемостимулятора приводит к “разветвлению” процесса, формированию новых положительных каналов связывания между стадиями сложного процесса [10], а отсюда - появление отклонения от аддитивности на диаграммах (рис. 5). При малом времени окисидирования имеют место значительные отклонение относи- 


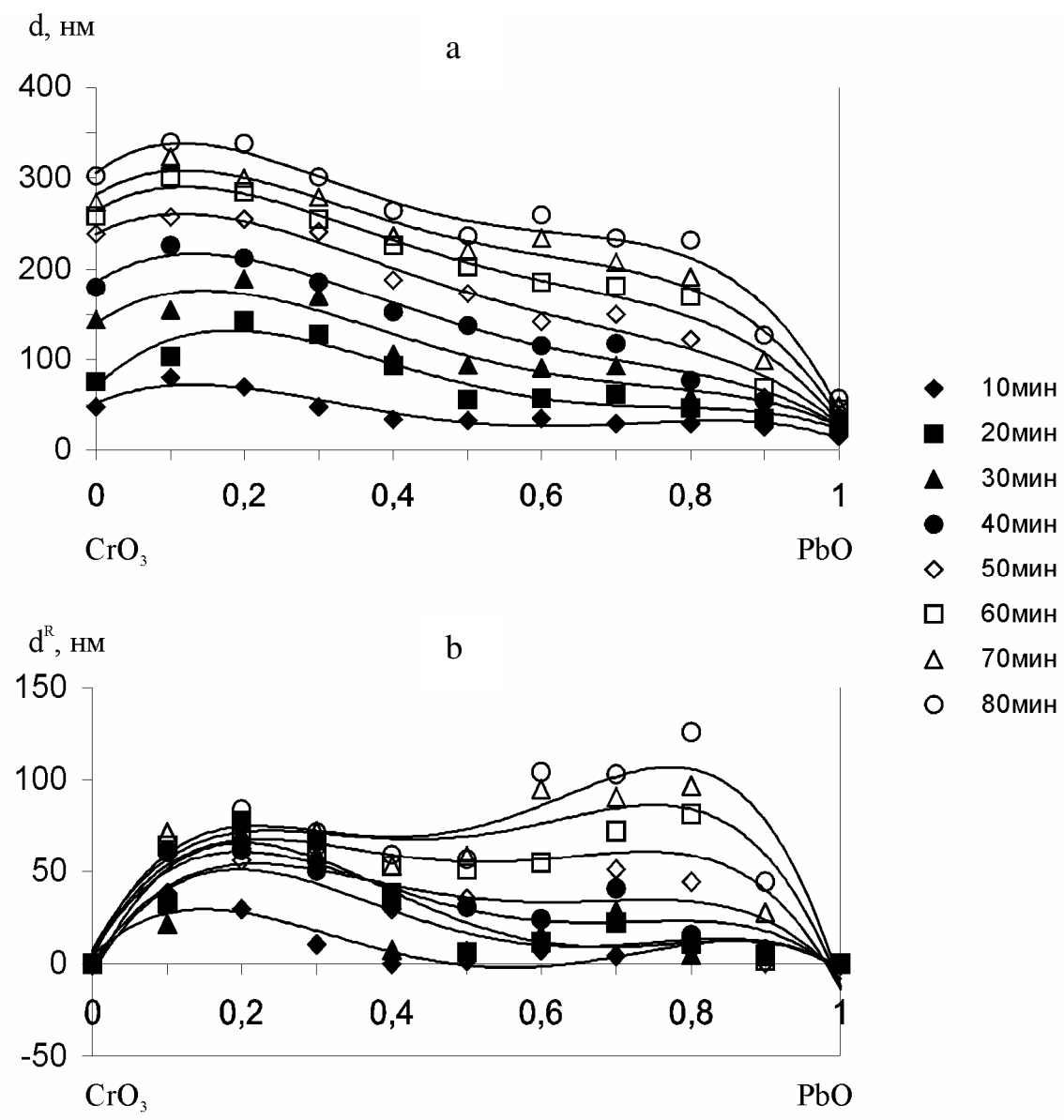

Рис. 5. Зависимость толщины $(a)$ и относительной интегральной толщины $(b)$ оксидной пленки на GaAs oт состава композиции хемостимуляторов $\mathrm{CrO}_{3}+\mathrm{PbO}$ при $500{ }^{\circ} \mathrm{C}$

[Fig. 5. Dependence of the thickness $(a)$ and relative integral thickness $(b)$ of the oxide films on GaAs from the composition of chemostimulators $\mathrm{CrO}_{3}+\mathrm{PbO}$ at $\left.500{ }^{\circ} \mathrm{C}\right]$

тельной интегральной толщины в области чистого $\mathrm{CrO}_{3}$ от аддитивного значения, с увеличением времени процесса нарастает вклад $\mathrm{PbO}$ в процесс термооксидирования.

Образующиеся в момент разложения самого сильного окислителя в системе - исходного $\mathrm{CrO}_{3}$ промежуточные оксиды хрома, а также продукт $\mathrm{Cr}_{2} \mathrm{O}_{3}$ в активной форме $\mathrm{Cr}_{2} \mathrm{O}_{3(\mathrm{r})}$ наряду с $\mathrm{PbO}$ могут взаимодействовать с галлием подложки, передавая ему кислород, и тем самым подавлять атаку галлия на $\mathrm{As}_{2} \mathrm{O}_{3}$ по реакции $2 \mathrm{Ga}+\mathrm{As}_{2} \mathrm{O}_{3} \rightarrow \mathrm{Ga}_{2} \mathrm{O}_{3}+$ $2 \mathrm{As}$, создавая так называемый положительный канал связывания [10]. Явным доказательством протекания этих процессов служит наличие хрома и свинца в выращенных слоях, что подтверждено методами ИКС, ЛРСМА, РФА. Образование хромата свинца можно назвать конкурирующим процессом, способствующим, с одной стороны, образованию нового дополнительного канала, а с другой - приводящим к некоторому торможению хе- мостимулирующего воздействия, что четко видно из диаграмм “состав - свойство” (рис. 5).

Зависимость толщины выращенной на GaAs оксидной пленки от состава композиции оксидов $\left(\mathrm{CrO}_{3}+\mathrm{V}_{2} \mathrm{O}_{5}\right)$ представлена на рис. 6. С увеличением времени окисидирования волна положительного отклонения смещается в сторону составов, обогащенных оксидом ванадия. Практически во всем интервале составов отклонение от аддитивности носит знакопеременный характер. Оксид ванадия, как и оксид хрома, является окислителем, однако обладает менее кислотными свойствами, чем $\mathrm{CrO}_{3}$. В данном случае $\mathrm{V}_{2} \mathrm{O}_{5}$ стимулирует разложение $\mathrm{CrO}_{3}$ по следующей цепочке: $\mathrm{Cr}_{3} \mathrm{O}_{8} \rightarrow \mathrm{Cr}_{2} \mathrm{O}_{5} \rightarrow$ $\mathrm{Cr}_{2} \mathrm{O}_{3}$ за счет связывания конечного продукта разложения (данные РФА) Это приводит к удалению из системы наиболее сильного стимулятора $\left(\mathrm{CrO}_{3}\right)$ и соответственно к уменьшению толщины оксидной пленки на GaAs, полученной под воздействием композиций, обогащенных $\mathrm{V}_{2} \mathrm{O}_{5}$. 


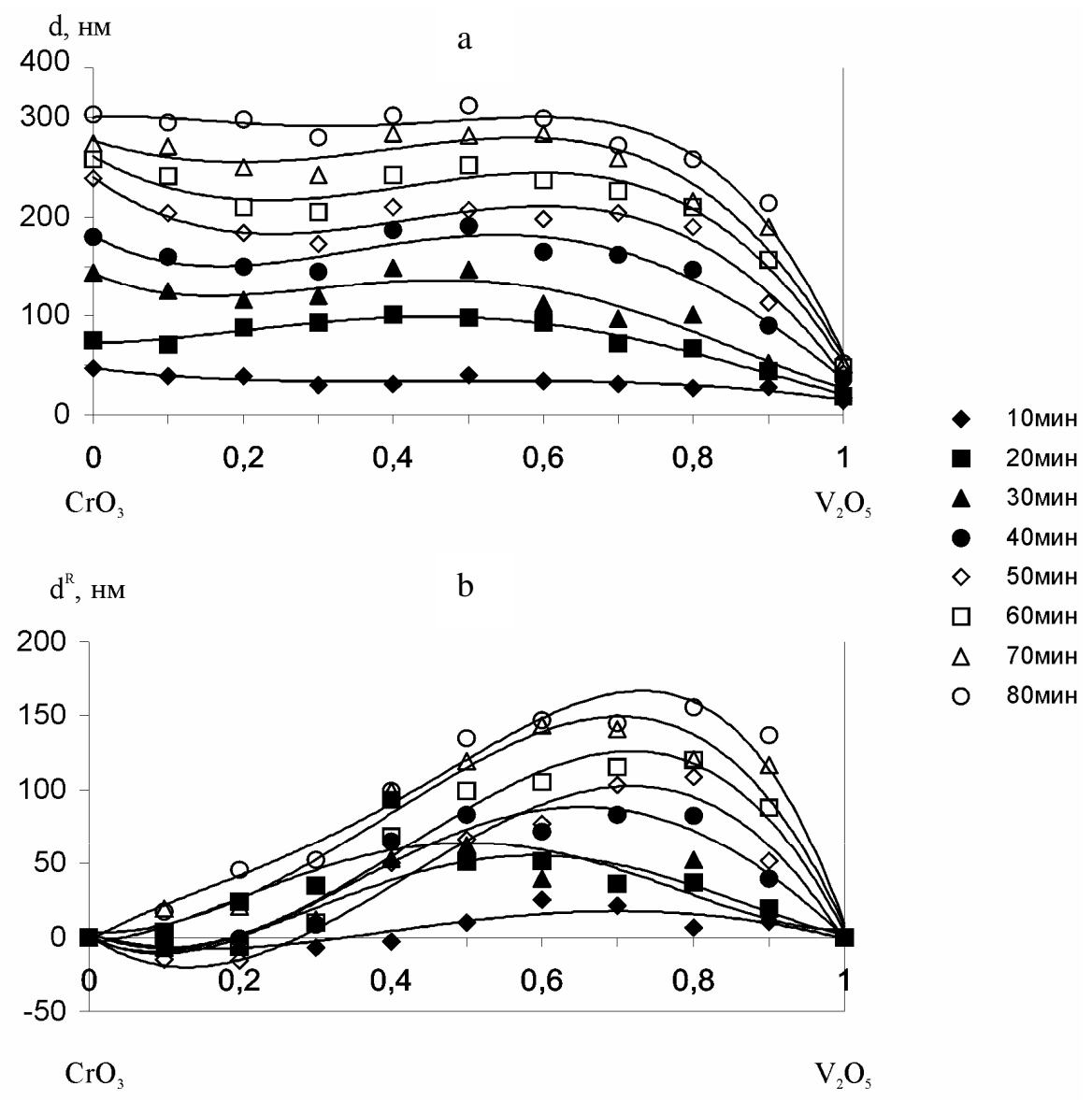

Рис. 6. Зависимость толщины $(a)$ и относительной интегральной толщины $(b)$ оксидной пленки на GaAs от состава композиции $\mathrm{CrO}_{3}+\mathrm{V}_{2} \mathrm{O}_{5}$ при $500{ }^{\circ} \mathrm{C}$

[Fig. 6. Dependence of thickness $(a)$ and relative integral thickness $(b)$ of the oxide film on GaAs on composition of $\mathrm{CrO}_{3}+\mathrm{V}_{2} \mathrm{O}_{5}$ at $\left.500^{\circ} \mathrm{C}\right]$

Положительное отклонение от аддитивности при эквимолярном соотношении связано с частичным образованием $\mathrm{CrVO}_{4}$ (РФА). Однако наличие его остается на уровне предположения, так как по низким интенсивностям линий на рентгенограммах нельзя утверждать о существовании именно этой фазы, тем более что данным значениям межплоскостного расстояния соответствуют и другие фазы, а именно $\mathrm{Cr}_{2} \mathrm{O}_{3}$ и $\mathrm{V}_{2} \mathrm{O}_{5}$. Необходимо отметить, что для эквимолярного состава отожженной при $525{ }^{\circ} \mathrm{C}$ композиции оксидов обнаружена фаза $\mathrm{V}_{2} \mathrm{O}_{3}$ (с максимальной интенсивностью). Наличие данного оксида также способствует увеличению разветвления процесса и усилению темпа прироста толщины пленки.

В работах [22-24] изложены результаты исследования термооксидирования GaAs под воздействием композиций, в которых одним из компонентов является оксид одного и того же элемента, но в разных степенях окисления. В качестве та- кого $d$-элемента был выбран марганец в степенях окисления +2 и +4 , а второго компонента $-\mathrm{PbO}$ или $\mathrm{V}_{2} \mathrm{O}_{5}$.

Для процесса термооксидирования GaAs под воздействием композиций $\mathrm{MnO}_{2}+\mathrm{PbO}$ отклонение толщины оксидной пленки на поверхности GaAs от аддитивности отрицательно во всем диапазоне составов и увеличивается с ростом времени. Подобная ситуация уже имела место при оксидировании GaAs под воздействием композиций оксидов р-элементов. Знакопеременное отклонение от аддитивности, характерное для термооксидирования $\mathrm{GaAs}$ под воздействием композиций с участием $\mathrm{PbO}$, отсутствует (рис. 7, 8).

После отжига $\left(560{ }^{\circ} \mathrm{C}, 30\right.$ мин) композиции $\mathrm{MnO}_{2}+\mathrm{PbO}$ обнаружено большое разнообразие оксидных фаз с различными степенями окисления катионообразователей (РФА). Имеет место превращение $\mathrm{MnO}_{2}$ в $\mathrm{Mn}_{3} \mathrm{O}_{4}$ и протекает оно интенсивно (поскольку происходит одновременное окисление 

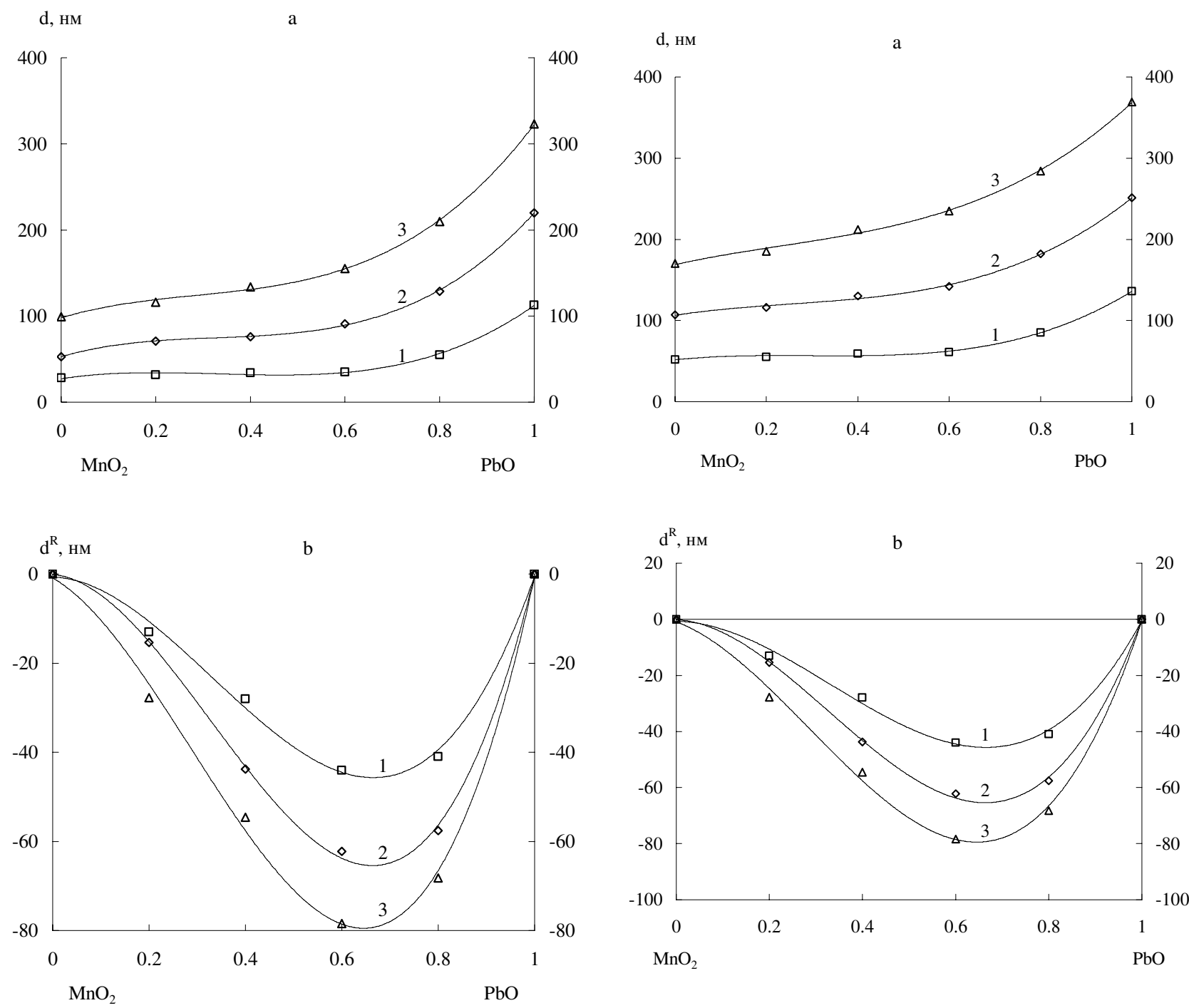

Рис. 7. Концентрационная зависимость толщины оксидной пленки ( $a$ ) и относительной интегральной толщины (b) за время: 1 - 10 мин, 2 - 30 мин, 3 60 мин при $530{ }^{\circ} \mathrm{C}$

[Fig. 7. Concentration dependence of the thickness of the oxide film $(a)$ and integrated relative thickness $(b)$ for time: $1-10 \mathrm{~min}, 2-30 \mathrm{~min}, 3-60 \mathrm{~min}$ at $530^{\circ} \mathrm{C}$ ]

оксида свинца (II)), что и приводит к отрицательному во всем интервале составов отклонению от аддитивности. Продуктами окисления оксида свинца (II) под действием оксида марганца (IV): $\mathrm{MnO}_{2} \rightarrow$ $\mathrm{Mn}_{3} \mathrm{O}_{4}$ являются $\mathrm{Pb}_{3} \mathrm{O}_{4}$, и даже $\mathrm{PbO}_{2}$. Таким образом, при совместном введении оксида марганца (IV) с оксидом свинца (II), эти хемостимуляторы оказывают взаимное влияние друг на друга еще в контейнере (введение хемостимуляторов способом 1 [18]). Это отражается превращением исходных оксидов в соединения с другими степенями окисления, что меняет режим испарения и является одним из факторов их совместного воздействия

Рис. 8. Концентрационная зависимость толщины оксидной пленки $(a)$ и относительной интегральной толщины $(b)$ за время: 1 - 10 мин, 2 - 30 мин, 3 60 мин при $560{ }^{\circ} \mathrm{C}$

[Fig. 8. Concentration dependence of the thickness of the oxide film $(a)$ and integrated relative thickness $(b)$ for time: $1-10 \mathrm{~min}, 2-30 \mathrm{~min}, 3-60 \mathrm{~min}$ at $560^{\circ} \mathrm{C}$ ]

на процесс термооксидирования GaAs.

Методами РСФА и ИКС установлено включение оксидов-хемостимуляторов в растущую на поверхности GaAs оксидную пленку. Для количественного определения содержания хемостимуляторов в оксидной пленке использовался метод ЛРСМА.

Полученные данные подтверждают результаты ИКС о включении свинца в результирующую оксидную пленку на поверхности GaAs, причем его содержание превышает таковое для марганца в случае обоих исследованных составов, что и следовало ожидать, учитывая диссоциативный харак- 
тер испарения $\mathrm{MnO}_{2}$. Все элементы в пленке находятся в окисленном состоянии (значительное содержание кислорода).

Поскольку при этом способе введения хемостимуляторов в систему их попадание на поверхность GaAs осуществляется через газовую фазу, что и обеспечивает связывание двух подсистем (контейнер с композицией и оксидируемый образец), исследование ее состава в зависимости от состава композиции необходимо для выяснения природы процессов, приводящих к отклонению от аддитивности. Методом масс-спектрометрии установлено уменьшение содержания в паровой фазе, по сравнению с испарением индивидуального $\mathrm{PbO}$, молекулярных форм оксида свинца (на 20-50 \%) и увеличение содержания неокисленного свинца (практически в два раза), что особенно хорошо заметно для композиций, обогащенных $\mathrm{PbO}$. Такое обеднение паровой фазы кислородсодержащими фрагментами испарения $\mathrm{PbO}$ приводит к замедлению роста пленки на поверхности GaAs и отрицательному отклонению от аддитивности в зависимости относительной интегральной толщины от состава композиции оксидов-хемостимуляторов (рис. 7, 8).

При термооксидировании GaAs под воздействием композиций $\mathrm{MnO}_{2}+\mathrm{V}_{2} \mathrm{O}_{5}$ имеет место знакопеременное отклонение от аддитивности, но с течением времени происходит усиление положительного отклонения (рис. 9).

В композициях после выдержки в токе кислорода при $560^{\circ} \mathrm{C}$ в течение 30 мин. обнаружены $\mathrm{V}_{2} \mathrm{O}_{5}, \mathrm{Mn}_{2} \mathrm{O}_{3}$ и $\mathrm{Mn}_{3} \mathrm{O}_{4}, \mathrm{MnO}_{2}$ (РФА). Таким обра3ом, в композиции с $\mathrm{V}_{2} \mathrm{O}_{5}$ происходит менее полное восстановление $\mathrm{MnO}_{2}$ по сравнению с композициями $\mathrm{MnO}_{2}+\mathrm{PbO}$, о чем свидетельствует образование $\mathrm{Mn}_{2} \mathrm{O}_{3}\left(\mathrm{MnO}_{2} \cdot \mathrm{MnO}\right)$, а не только $\mathrm{Mn}_{3} \mathrm{O}_{4}$ $\left.\left(\mathrm{MnO}_{2} \cdot 2 \mathrm{MnO}\right)\right)$, что способствует сохранению активности хемостимулятора и приводит к положительному отклонению от аддитивности (рис. 9). Оба эти оксида являются эффективными транзиторами кислорода (ускорение формирования пленок под воздействием $\mathrm{V}_{2} \mathrm{O}_{5}$ до 4 раз, $\mathrm{MnO}_{2}$ - до 2 раз) и соответственно в состав оксидных пленок входят как марганец, так и ванадий (РСФА и ИКС). Наличие линий, отвечающих связи $\mathrm{Ga}-\mathrm{O}$ (420$\left.440,670 \mathrm{~cm}^{-1}\right)$, по аналогии с присущими эталонам (собственное оксидирование), говорит об образовании $\mathrm{Ga}_{2} \mathrm{O}_{3}$. Также имеются полосы поглощения, соответствующие связи As-O $\left(480,900 \mathrm{~cm}^{-1}\right)$.

Для композиции 80 мол. $\% \mathrm{~V}_{2} \mathrm{O}_{5}+20$ мол. \% $\mathrm{MnO}_{2}$ в пленке на поверхности $\mathrm{GaAs}$ соотношение хемостимуляторов составляет $80.2 \% \mathrm{~V}+19.8 \%$

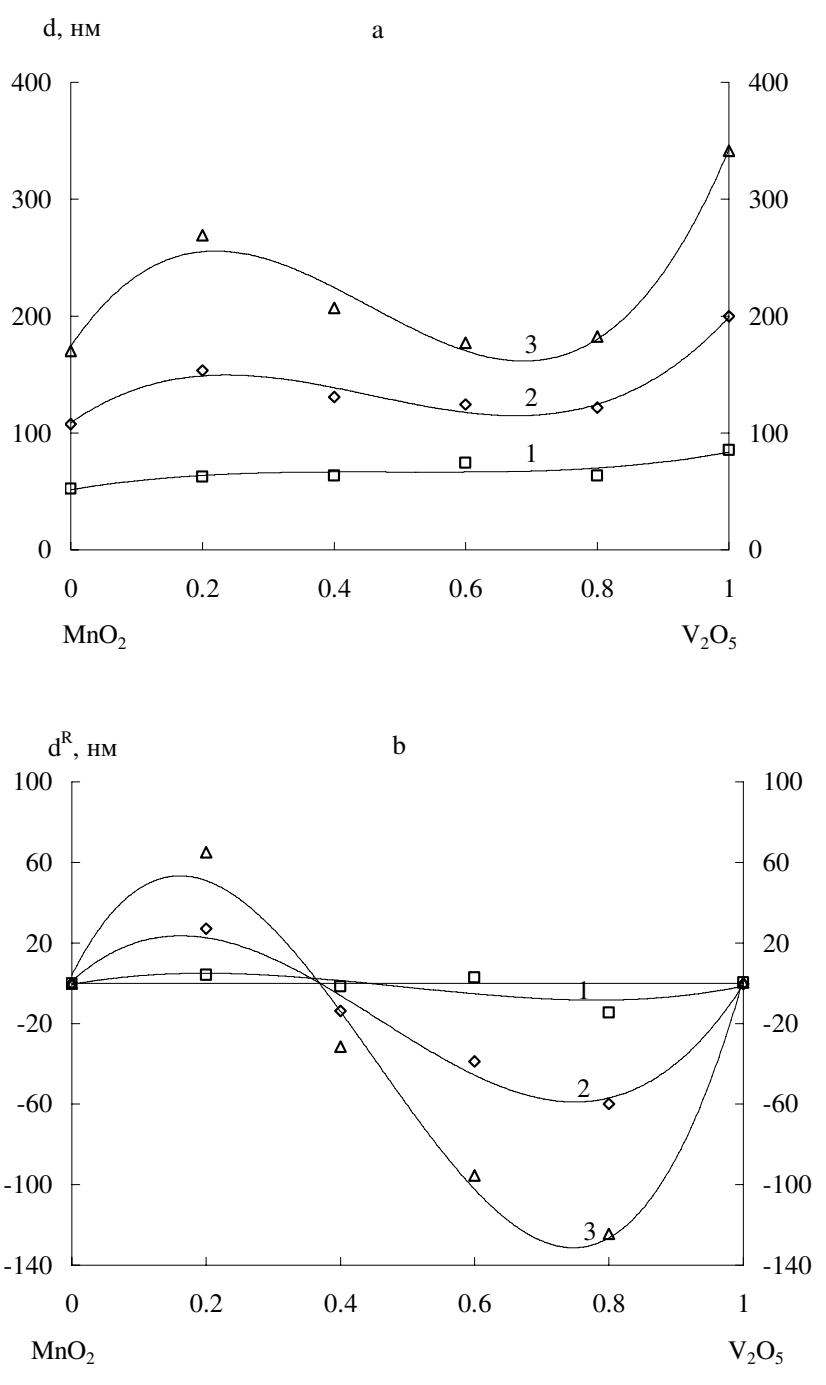

Рис. 9. Концентрационная зависимость толщины оксидного пленки $(a)$ и относительной интегральной толщины $(b)$ за время: 1 - 10 мин, 2 - 30 мин, 3 60 мин при $560{ }^{\circ} \mathrm{C}$

[Fig. 9. Concentration dependence of the thickness of the oxide film $(a)$ and integrated relative thickness $(b)$ for time: $1-10 \mathrm{~min}, 2-30 \mathrm{~min}, 3-60 \mathrm{~min}$ at $560{ }^{\circ} \mathrm{C}$ ]

$\mathrm{Mn}$; а для композиции 20 мол. $\% \mathrm{~V}_{2} \mathrm{O}_{5}+80$ мол. \% $\mathrm{MnO}_{2}-28.1 \% \mathrm{~V}+71.9 \% \mathrm{Mn}$ (ЛРСМА). Поскольку $\mathrm{V}_{2} \mathrm{O}_{5}$ является более эффективным хемостимулятором, нежели $\mathrm{MnO}_{2}$, т. е. обусловливает большие значения толщины оксидной пленки на GaAs (рис. 9), его возросшее по сравнению с составом композиции содержание в оксидной пленке оказывается достаточным для увеличения толщины в сравнении с аддитивным значением.

Нелинейные зависимости толщины оксидной пленки на поверхности GaAs от состава композиций $\mathrm{MnO}+\mathrm{V}_{2} \mathrm{O}_{5}$ и $\mathrm{MnO}+\mathrm{PbO}$ существенно зависят от параметров оксидирования, особенно в случае 
$\mathrm{MnO}+\mathrm{V}_{2} \mathrm{O}_{5}$ (рис. 10). Для «MnO+PbO»-процесса имеет место знакопеременное отклонение от аддитивности с минимумом вблизи состава $70 \% \mathrm{PbO}$ $+30 \% \mathrm{MnO}$. С ростом параметров оксидирования отрицательное отклонение от аддитивной прямой усиливается и расширяется по оси состава, вплоть до полного исчезновения положительного отклонения при $560{ }^{\circ} \mathrm{C}, 60$ мин. Для « $\mathrm{MnO}+\mathrm{V}_{2} \mathrm{O}_{5} »-$ процесса на графиках зависимостей $d^{R}$ от состава композиции с увеличением температуры оксидирования от 530 до $560{ }^{\circ} \mathrm{C}$ происходит смена положительного отклонения от аддитивности во всем интервале составов на знакопеременное.

Методом РФА для композиций $\mathrm{MnO}+\mathrm{PbO}$ (отжиг в режиме $560^{\circ} \mathrm{C}, 30$ мин) обнаружено большое разнообразие оксидных фаз с различными степенями окисления катионообразователей. Оксид мар- ганца (II) в отожженных навесках отсутствует, т. е. в условиях эксперимента происходит его превращение в $\mathrm{MnO}_{2}\left(300^{\circ} \mathrm{C}\right)$, а затем в $\mathrm{Mn}_{3} \mathrm{O}_{4}\left(540^{\circ} \mathrm{C}\right)$. $\mathrm{PbO}$, напротив, практически не претерпевает окислительно-восстановительных превращений, за исключением композиций, обогащенных $\mathrm{MnO}$, где имеются пики, характерные для $\mathrm{Pb}_{3} \mathrm{O}_{4}$, и даже, в незначительной степени, $\mathrm{PbO}_{2}$, что, как уже отмечалось для композиции $\mathrm{MnO}_{2}+\mathrm{PbO}$, связано с окисляющим действием образующегося $\mathrm{MnO}_{2}$, в том числе и в составе $\mathrm{Mn}_{3} \mathrm{O}_{4}$.

$\mathrm{B}$ композиции $\mathrm{MnO}+\mathrm{V}_{2} \mathrm{O}_{5}$ имеет место переход $\mathrm{MnO} \rightarrow \mathrm{MnO}_{2} \rightarrow \mathrm{Mn}_{3} \mathrm{O}_{4}$, при этом для составов, обедненных $\mathrm{MnO}$, отсутствуют не только сам оксид марганца (II), но и продукт его окисления $\left(\mathrm{MnO}_{2}\right)$. $\mathrm{V}_{2} \mathrm{O}_{5}$ частично превращается в $\mathrm{V}_{2} \mathrm{O}_{3}$ (хотя его количества незначительны), что может быть обуслов-
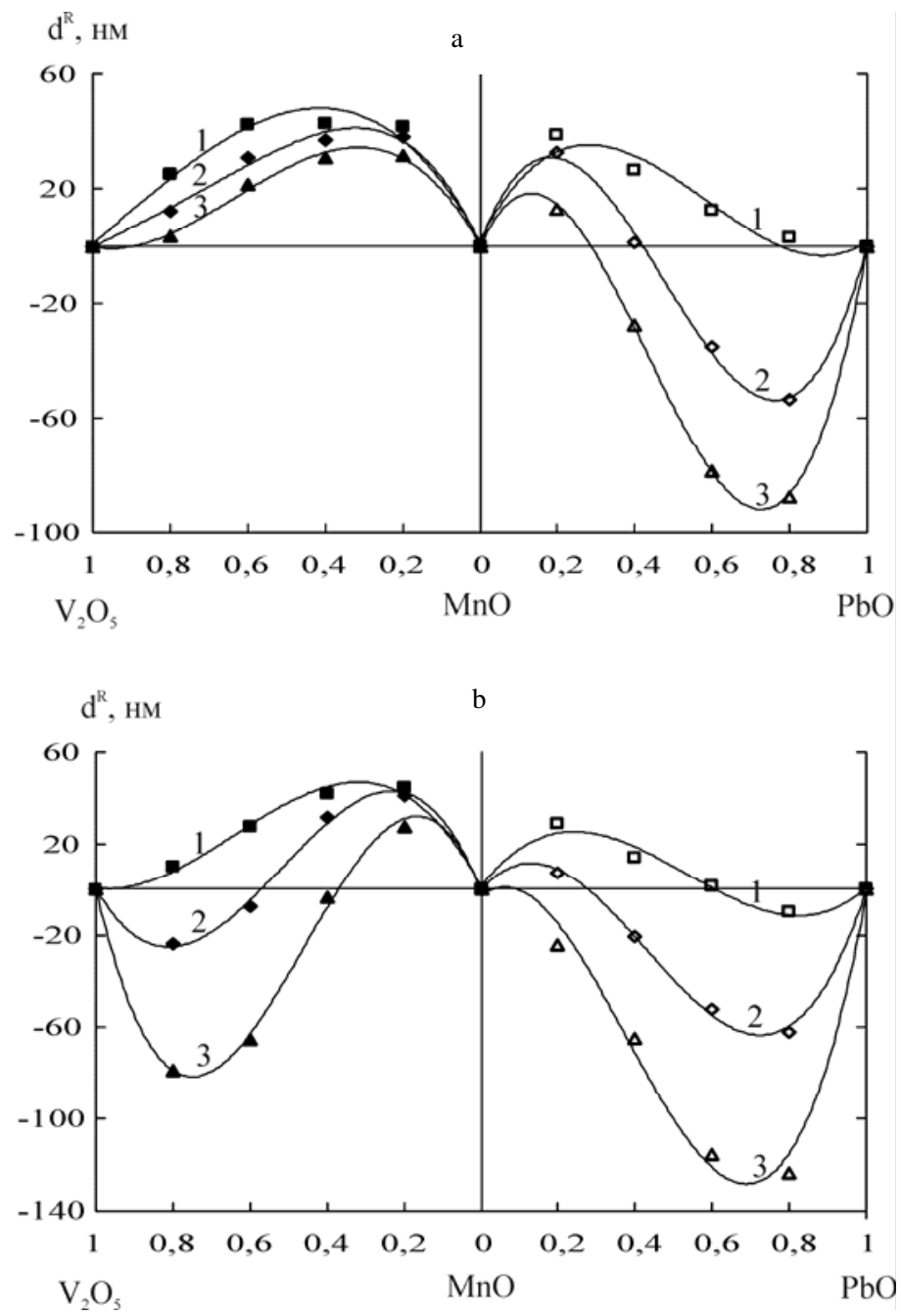

Рис. 10. Относительная интегральная толщина оксидной пленки на поверхности GaAs, как функция состава композиции хемостимуляторов $530{ }^{\circ} \mathrm{C}(a)$ и $560{ }^{\circ} \mathrm{C}(b)$ за время: $1-10$ мин, $2-30$ мин, $3-60$ мин

[Fig. 10. Relative integral thickness of the oxide film on the surface of GaAs, as a function of the composition of chemostimulators $530{ }^{\circ} \mathrm{C}(a)$ and $560{ }^{\circ} \mathrm{C}(b)$ for the time: $1-10 \mathrm{~min}, 2-30 \mathrm{~min}, 3-60 \mathrm{~min}$ ] 
лено как передачей кислорода оксиду марганца (II) на начальных этапах процесса при его окислении до $\mathrm{MnO}_{2}$, в дальнейшем претерпевающего превращение в $\mathrm{Mn}_{3} \mathrm{O}_{4}$, так и легкостью взаимных переходов $\mathrm{V}^{+3} \rightarrow \mathrm{V}^{+5}$. Накопление в системе эффективного хемостимулятора $\mathrm{MnO}_{2}$ приводит к большим значениям толщины оксидной пленки на поверхности GaAs и в области составов, изначально обогащенных $\mathrm{MnO}$, имеет место положительное отклонение от аддитивности (рис. $10 b$ ).

Сформированные на GaAs пленки состоят преимущественно из $\mathrm{Ga}_{2} \mathrm{O}_{3}$ и $\mathrm{As}_{2} \mathrm{O}_{3}$ (ИКС, ЛРСМА). В случае совместного воздействия $\mathrm{MnO}_{\text {и }} \mathrm{O}_{2} \mathrm{O}_{5}$ соотношение хемостимуляторов в композиции изменяется от 4:1 до 1:4. В то же время в полученной на поверхности GaAs пленке их соотношение практически постоянно: 24.60 ат. \% и 14.51 ат. \%; 24.22 ат. $\%$ и 14.71 ат. $\%$ соответственно (или $1.7: 1$ и 1.6:1). Подобное постоянство соотношений хемостимуляторов в оксидной пленке на поверхности GaAs при широком изменении состава композиции $\mathrm{MnO}+\mathrm{V}_{2} \mathrm{O}_{5}$ является косвенным свидетельством испарения не только собственно оксидов марганца и ванадия, но и некоторых продуктов их взаимодействия (например, ванадата марганца), что согласуется с наличием для этой композиции промежуточных фаз неустановленного состава (РФА).

В обобщенном виде полученные закономерности представлены в табл. 1 и на рис. 11. Общей тенденцией развития нелинейных эффектов с температурой и временем практически для всех систем является усиление отрицательного отклонения от аддитивности и ослабление положительного, за исключением композиций с участием оксида хрома
(VI), когда имеет место не только положительное отклонение от аддитивной прямой во всем интервале составов композиции оксидов-хемостимуляторов, но и усиление этого эффекта при увеличении параметров процесса.

Из рис. 11 следует четкая зависимость характера нелинейного эффекта от природы оксидовхемостимуляторов композиции и наличия или отсутствия между ними химического взаимодействия. Если между оксидами композиции имеет место кислотно-основное или окислительно-восстановительное взаимодействие (а не просто превращение одних оксидных форм в другие), то будет иметь место положительное отклонение от аддитивности, усиливающееся с ростом времени и температуры процесса, как например, для композиций с участием оксида хрома (VI) (интенсификация взаимодействий, приводящих к новым активным формам и путям воздействия на рост пленки на поверхности полупроводника). По мере ослабления кислотно-основных и окислительно-восстановительных взаимодействий и наличия только индивидуальных переходов между оксидными формами хемостимуляторов положительное отклонение от аддитивности сменяется знакопеременным (например, композиции с участием оксида свинца или оксидов марганца) и это появляющееся отрицательное отклонение усиливается с температурой и временем, поскольку новые образующиеся оксидные формы менее активны по сравнению с исходной (например, $\mathrm{Mn}_{2} \mathrm{O}_{3}$ и $\mathrm{Mn}_{3} \mathrm{O}_{4}$ по сравнению с $\mathrm{MnO}_{2}$ ). И, наконец, в случае практически полного отсутствия как взаимодействий между оксидами композиции, так и их химических превращений

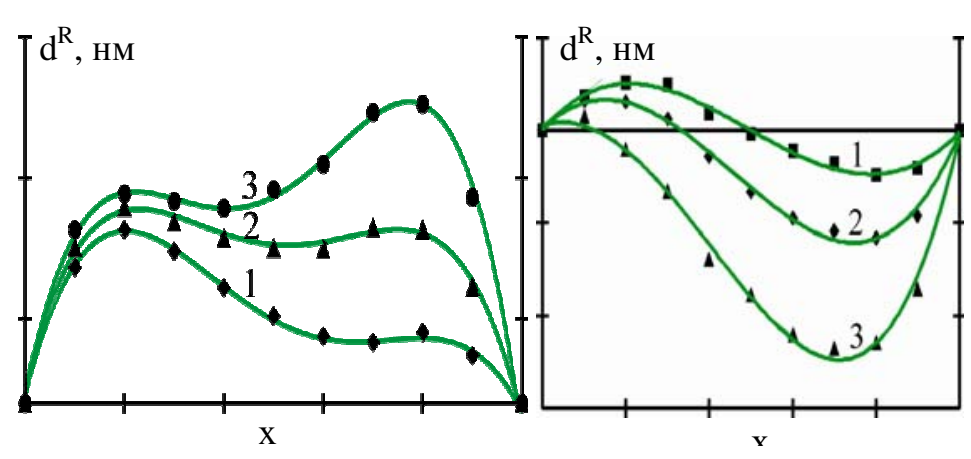

$\mathrm{b}$

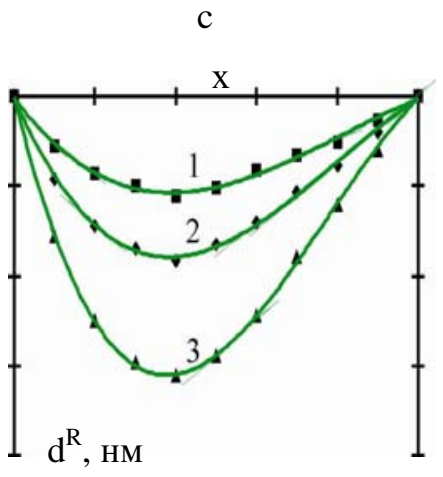

Рис. 11. Зависимость нелинейных эффектов от природы хемостимуляторов: $a$ - ярко выраженные кислотноосновные и окислительно-восстановительные взаимодействия; $b$ - слабо выраженные кислотно-основные и окислительно-восстановительные взаимодействия; с - кислотно-основных и окислительно-восстановительных взаимодействий практически нет

[Fig. 11. Dependence of nonlinear effects on the nature of chemostimulating: $a$ - pronounced acid-base and redox interactions; $b$ - mild acid-base and redox interactions; $c$ - acid-base and redox interactions are almost there] 
Таблица 1. Развитие нелинейных эффектов совместного воздействия хемостимуляторов с температурой и временем

[Table 1. The development of nonlinear effects of the combined effects of chemostimulators with temperature and time]

\begin{tabular}{|c|c|c|c|}
\hline \multirow{2}{*}{$\begin{array}{c}\text { Композиций } \\
\text { хемостимуляторов } \\
\text { [Chemostimulators } \\
\text { compositions] }\end{array}$} & \multirow{2}{*}{$\begin{array}{c}\text { Характер отклонения от } \\
\text { аддитивности } \\
\text { [The nature of the } \\
\text { deviation from additivity] }\end{array}$} & \multicolumn{2}{|c|}{$\begin{array}{l}\text { Динамика изменения эффекта } \\
\text { [Dynamics of change of effect] }\end{array}$} \\
\hline & & $\begin{array}{c}\text { с температурой } \\
\text { [with temperature] }\end{array}$ & $\begin{array}{l}\text { со временем } \\
\text { [with time] }\end{array}$ \\
\hline 1 & 2 & 3 & 4 \\
\hline \multicolumn{4}{|c|}{$\begin{array}{l}\text { Композиции оксид } p \text {-элемента }+ \text { оксид } p \text {-элемента } \\
\text { nposition of oxide of the } p \text {-element }+ \text { oxide of the } p \text {-element] }\end{array}$} \\
\hline $\mathrm{Sb}_{2} \mathrm{O}_{3}+\mathrm{Bi}_{2} \mathrm{O}_{3}$ & $\begin{array}{l}\text { Отрицательное } \\
\text { [Negative] }\end{array}$ & $\begin{array}{c}\text { Усиление } \\
\text { [Intensification] }\end{array}$ & $\begin{array}{c}\text { Усиление } \\
\text { [Intensification] }\end{array}$ \\
\hline \multirow[t]{2}{*}{$\mathrm{Sb}_{2} \mathrm{O}_{3}+\mathrm{PbO}$} & \multirow[t]{2}{*}{$\begin{array}{l}\text { Знакопеременное } \\
\text { [Alternating] }\end{array}$} & $\begin{array}{c}\text { Усиление отрицательного } \\
\text { отклонения } \\
\text { [Intensification of the } \\
\text { negative deviation] }\end{array}$ & $\begin{array}{c}\text { Усиление отрицательного } \\
\text { отклонения } \\
\text { [Intensification of the } \\
\text { negative deviation] }\end{array}$ \\
\hline & & $\begin{array}{c}\text { Ослабление положительно- } \\
\text { го отклонения } \\
\text { [Weakening positive } \\
\text { deviation] }\end{array}$ & $\begin{array}{c}\text { Ослабление положительно- } \\
\text { го отклонения } \\
\text { [Weakening positive } \\
\text { deviation] }\end{array}$ \\
\hline \multirow[t]{2}{*}{$\mathrm{Bi}_{2} \mathrm{O}_{3}+\mathrm{PbO}$} & \multirow[t]{2}{*}{$\begin{array}{l}\text { Знакопеременное } \\
\text { [Alternating] }\end{array}$} & $\begin{array}{c}\text { Усиление отрицательного } \\
\text { отклонения } \\
\text { [Intensification of the } \\
\text { negative deviation] }\end{array}$ & $\begin{array}{c}\text { Усиление отрицательного } \\
\text { отклонения } \\
\text { [Intensification of the } \\
\text { negative deviation] }\end{array}$ \\
\hline & & $\begin{array}{c}\text { Ослабление положительно- } \\
\text { го отклонения } \\
\text { [Weakening of the positive } \\
\text { deviation] }\end{array}$ & $\begin{array}{c}\text { Ослабление положительно- } \\
\text { го отклонения } \\
\text { [Weakening of thepositive } \\
\text { deviation] }\end{array}$ \\
\hline \multicolumn{4}{|c|}{$\begin{array}{l}\text { Композиции оксид } d \text {-элемента }+ \text { оксид } p \text {-элемента } \\
\text { pposition of oxide of the } d \text {-element }+ \text { of the oxide } p \text {-element] }\end{array}$} \\
\hline $\mathrm{CrO}_{3}+\mathrm{PbO}$ & $\begin{array}{l}\text { Положительное } \\
\text { [Positive] }\end{array}$ & $\begin{array}{c}\text { Усиление } \\
\text { [Intensification] }\end{array}$ & $\begin{array}{c}\text { Усиление } \\
\text { [Intensification] }\end{array}$ \\
\hline $\mathrm{PbO}+\mathrm{MnO}_{2}$ & $\begin{array}{l}\text { Отрицательное } \\
\text { [Negative] }\end{array}$ & $\begin{array}{c}\text { Ослабление отрицательно- } \\
\text { го отклонения } \\
\text { [Weakening of the negative } \\
\text { deviation] }\end{array}$ & $\begin{array}{c}\text { Усиление отрицательного } \\
\text { отклонения } \\
\text { [Intensification of the } \\
\text { negative deviation] }\end{array}$ \\
\hline $\mathrm{PbO}+\mathrm{MnO}$ & $\begin{array}{l}\text { Знакопеременное } \\
\text { [Alternating] }\end{array}$ & $\begin{array}{c}\text { Усиление отрицательного } \\
\text { отклонения } \\
\text { [Intensification of the } \\
\text { negative deviation] } \\
\end{array}$ & $\begin{array}{c}\text { Усиление отрицательного } \\
\text { отклонения } \\
\text { [Intensification of the } \\
\text { negative deviation] }\end{array}$ \\
\hline \multicolumn{4}{|c|}{$\begin{array}{c}\text { Композиции оксид } d \text {-элемента }+ \text { оксид } d \text {-элемента } \\
\text { [Composition of oxide of the } d \text {-element }+ \text { oxide of the } d \text {-element] }\end{array}$} \\
\hline $\mathrm{CrO}_{3}+\mathrm{V}_{2} \mathrm{O}_{5}$ & $\begin{array}{l}\text { Положительное } \\
\text { [Positive] }\end{array}$ & $\begin{array}{c}\text { Усиление } \\
\text { [Intensification] }\end{array}$ & $\begin{array}{c}\text { Усиление } \\
\text { [Intensification] }\end{array}$ \\
\hline \multirow[t]{2}{*}{$\mathrm{V}_{2} \mathrm{O}_{5}+\mathrm{MnO}_{2}$} & \multirow{2}{*}{\multicolumn{2}{|c|}{$\begin{array}{l}\text { Знакопеременное при низкой температуре } \\
\text { [Alternating at low temperature] }\end{array}$}} & $\begin{array}{c}\text { Усиление отрицательного } \\
\text { отклонения } \\
\text { [Intensification of the } \\
\text { negative deviation] }\end{array}$ \\
\hline & & & $\begin{array}{c}\text { Ослабление положительно- } \\
\text { го отклонения } \\
\text { [Weakening of the positive } \\
\text { deviation] }\end{array}$ \\
\hline
\end{tabular}


НЕЛИНЕЙНЫЕ ЭФФЕКТЫ СОВМЕСТНОГО ВОЗДЕЙСТВИЯ ОКСИДОВ $p$ - И $d$-ЭЛЕМЕНТОВ...

\begin{tabular}{|c|c|c|c|}
\hline 1 & 2 & 3 & 4 \\
\hline & \multirow{2}{*}{\multicolumn{2}{|c|}{$\begin{array}{l}\text { Знакопеременное при высокой температуре } \\
\text { [Alternating at high temperature] }\end{array}$}} & $\begin{array}{c}\text { Усиление отрицательного } \\
\text { отклонения } \\
\text { [Intensification of the } \\
\text { negative deviation] }\end{array}$ \\
\hline & & & $\begin{array}{c}\text { Усиление положительного } \\
\text { отклонения } \\
\text { [Intensification of the } \\
\text { positive deviation] }\end{array}$ \\
\hline \multirow[t]{3}{*}{$\mathrm{V}_{2} \mathrm{O}_{5}+\mathrm{MnO}$} & Полоя & $\begin{array}{l}\text { пературе } \\
\text { e] }\end{array}$ & $\begin{array}{l}\text { Ослабление положительно- } \\
\text { го отклонения } \\
\text { [Weakening of the positive } \\
\text { deviation] }\end{array}$ \\
\hline & \multirow{2}{*}{\multicolumn{2}{|c|}{$\begin{array}{c}\text { Знакопеременное при высокой температуре } \\
\text { [Alternating at high temperature] }\end{array}$}} & $\begin{array}{c}\text { Усиление отрицательного } \\
\text { отклонения } \\
\text { [Intensification of the } \\
\text { negative deviation] }\end{array}$ \\
\hline & & & $\begin{array}{c}\text { Ослабление положительно- } \\
\text { го отклонения } \\
\text { [Weakening of the positive } \\
\text { deviation] }\end{array}$ \\
\hline
\end{tabular}

имеет место отрицательное во всем интервале составов отклонение от аддитивности, усиливающееся при увеличении, как температуры, так и времени (воздействие композиции $\mathrm{Sb}_{2} \mathrm{O}_{3}+\mathrm{Bi}_{2} \mathrm{O}_{3}$ ).

Таким образом, все описанные композиции хемостимуляторов относятся к варианту $(a)$ рис. 2 . Очевидно, что отклонения от аддитивности совместного воздействия хемостимуляторов связаны именно с существованием их взаимного влияния друг на друга. В рассмотренных ниже работах представлены два направления развития исследований: с одной стороны -установление пространственной локализации связывающих взаимодействий между хемостимуляторами, а с другой - реализация других вариантов, представленных на рис. 2.

\section{ЭФФЕКТЫ СОВМЕСТНОГО ВОЗДЕЙСТВИЯ ОКСИДОВ p- И $d$-ЭЛЕМЕНТОВ} НА ТЕРМООКСИДИРОВАНИЕ GaАs ПРИ
ИХ ПРОСТРАНСТВЕННОМ РАЗДЕЛЕНИИ

Взаимное влияние между хемостимуляторами при их совместном воздействии на процесс термооксидирования GaAs может иметь различную пространственную локализацию - твердая фаза (собственно композиция хемостимуляторов), газообразная фаза (в процессе переноса хемостимуляторов от композиции к оксидируемой поверхности) и поверхности полупроводника (например, в виде конкуренции за активные центры или центры адсорбции). В каждом конкретном случае воз- можна как комбинация всех перечисленных вариантов, так и отсутствие какого-либо из них. Подход, решающий вопрос о пространственной локализации связывающих стадий, заключается в последовательном исключении возможных областей взаимовлияния (путем модификации условий эксперимента) и оценки изменения суммарного нелинейного эффекта.

В работах [25-30] установлена локализация взаимодействий между хемостимуляторами для всех описанных выше их композиций, за исключением таковых с участием оксида хрома (VI) (в силу специфики эксперимента, двухзонный метод).

Вначале рассмотрим композиции оксид $p$-элемента+оксид $p$-элемента (см. табл. 1). Первой из рассмотренных систем явилась композиция $\mathrm{Sb}_{2} \mathrm{O}_{3}+\mathrm{Bi}_{2} \mathrm{O}_{3}$. Были введены следующие обозначения: образцы с предварительно сформированным на их поверхности слоем собственного оксида (исключение взаимного влияния на поверхности) - серия $Б$, без такового - серия $A$; введение хемостимуляторов в окислительную атмосферу из единой композиции - режим $I$, пространственное разделение хемостимуляторов, исключающее их взаимное влияние в твердой фазе - peжим II (рис. 12).

При раздельном введении $\mathrm{Sb}_{2} \mathrm{O}_{3}$ и $\mathrm{Bi}_{2} \mathrm{O}_{3}$ налицо сохраняющееся отклонение от аддитивной прямой (рис. 12, кривая 2), следовательно, взаимное влияние оксидов все равно существует. Но поскольку в твердой фазе оно исключено то оно может иметь 

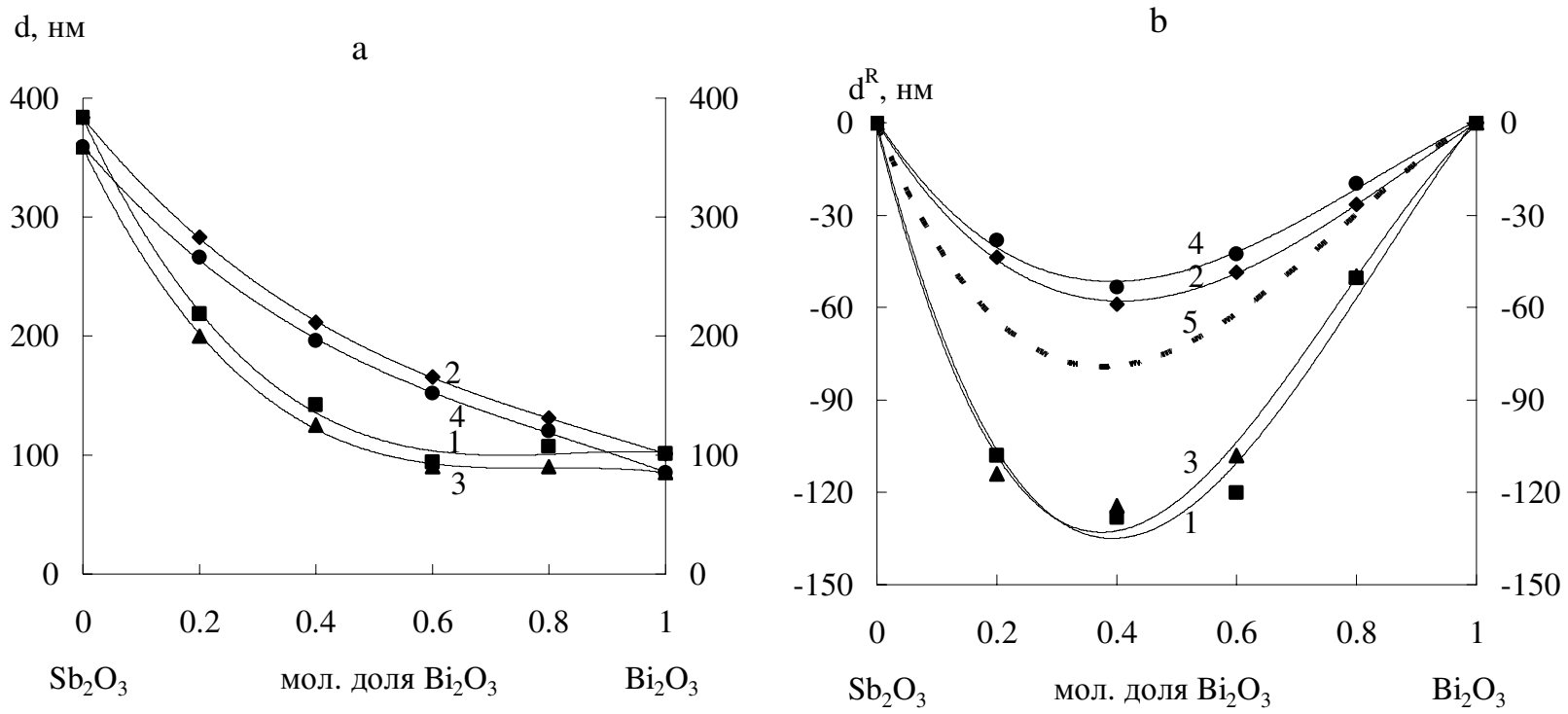

Рис. 12. Зависимости $d^{R}$ оксидной пленки на GaAs, полученной при $530{ }^{\circ} \mathrm{C}$ и времени оксидирования 40 мин, от состава композиции $\mathrm{Sb}_{2} \mathrm{O}_{3}+\mathrm{Bi}_{2} \mathrm{O}_{3}: 1$ - Серия А, Режим I; 2 - Серия А, Режим II; 3 - Серия Б, Режим I; 4 - Серия Б, Режим II; 5 - рассчитанный вклад твердофазных взаимодействий

[Fig. 12. Dependence of $d^{R}$ of the oxide film on GaAs obtained at $530^{\circ} \mathrm{C}$ and oxidation time of $40 \mathrm{~min}$ on composition $\mathrm{Sb}_{2} \mathrm{O}_{3}+\mathrm{Bi}_{2} \mathrm{O}_{3}: 1$ - Series A, Mode I; 2 - Series A, mode II; 3 - Series B, Mode I; 4 - Series B, mode II; 5 - calculated contribution of solid-phase interactions]

место или на поверхности полупроводника, или в газовой фазе, или и там, и там.

И при совместном, и при раздельном введении этих хемостимуляторов (режсимы I и II, кривые 1 и 2) обнаружено отрицательное отклонение от аддитивности, однако при совместном введении оно выражено существенно сильнее. Зависимость $d^{R}$ от состава композиции оксидов для образцов GaAs c предварительно выращенным оксидным подслоем (серия Б) практически совпадает с отвечающей оксидированию «чистой» поверхности GaAs (ceрия A) - как в режиме I (кривые 1 и 3), так и в режиме II (кривые 2 и 4). Замена поверхности образца с "чистой” на покрытую собственным оксидом практически не оказывает влияние на результирующую толщину оксидной пленки на поверхности GaAs.

Таким образом, взаимодействие хемостимуляторов на “чистой” поверхности GaAs либо вообще не имеет места, либо весьма незначительно. Такого результата можно было ожидать, учитывая, что даже после предварительной обработки поверхность GaAs не является атомарно чистой и всегда покрыта тонким слоем собственного оксида. Следовательно, ответственным за нелинейный эффект при раздельном воздействии хемостимуляторов, когда взаимодействие их в твердой фазе полностью исключено (кривые 2 и 4), явля- ется взаимное влияние оксидов-хемостимуляторов в газовой фазе.

Режим II (рис. 12, кривые 2 и 4) применен с целью исключения твердофазных взаимодействий, и нелинейный эффект обусловлен взаимным влиянием хемостимуляторов в газовой фазе. Была рассчитана теоретическая кривая в предположении одного только твердофазного взаимодействия хемостимуляторов (рис. 12, кривая 5) и показано, что вклады взаимодействий в твердой и газовой фазах соизмеримы, хотя твердофазные процессы все же преобладают.

При совместном введении хемостимуляторы равномерно распределены по поверхности GaAs, их содержание незначительно и сравнимо между собой (ЛРСМА). При раздельном введении сурьмы в пленках гораздо больше, нежели висмута. В то же время содержание висмута в пленке при раздельном введении хемостимуляторов почти в 10 раз меньше, чем при совместном, следовательно, в случае совместного воздействия $\mathrm{Sb}_{2} \mathrm{O}_{3}$ и $\mathrm{Bi}_{2} \mathrm{O}_{3}$ первый способствует включению второго в растущую пленку, в то время как сам $\mathrm{Bi}_{2} \mathrm{O}_{3}$ препятствует включению $\mathrm{Sb}_{2} \mathrm{O}_{3}$.

Таким образом, взаимодействия между $\mathrm{Sb}_{2} \mathrm{O}_{3}$ и $\mathrm{Bi}_{2} \mathrm{O}_{3}$, обусловливающие отклонения от аддитивности при их воздействии на термооксидирование $\mathrm{GaAs}$, локализованы в твердой и газовой фазах с 
соизмеримыми вкладами, а на поверхности GaAs практически не осуществляются.

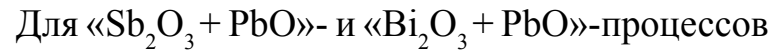
под влиянием пространственно разделенных оксидов суммарное отклонение от аддитивности выражено сильнее и носит более отрицательный характер по сравнению с их воздействием из единой композиции (рис. 13). Для обеих систем вклад твердофазных взаимодействий положителен, несмотря на суммарное отрицательное отклонение от аддитивности (рис. 13). Вклад паровой фазы, неустранимый из-за переноса через нее реагентов к поверхности GaAs, отрицателен и превосходит по абсолютной величине таковой для твердофазных взаимодействий, что и обусловливает суммарное отрицательное отклонение от аддитивной прямой.

Соотношение содержания оксидов в растущей пленке определяется давлением пара каждого из них. Поскольку $\mathrm{PbO}$ по этому показателю занимает промежуточное положение между $\mathrm{Sb}_{2} \mathrm{O}_{3}$ и $\mathrm{Bi}_{2} \mathrm{O}_{3}$ (давление насыщенного пара в условиях эксперимента составляет для $\mathrm{Sb}_{2} \mathrm{O}_{3} \sim 0.1$ Па, $\mathrm{PbO}$ $\sim 1 \cdot 10^{-2}$ Па, $\mathrm{Bi}_{2} \mathrm{O}_{3} \sim 1 \cdot 10^{-3}$ Па [31]), то его содержание больше, чем $\mathrm{Bi}_{2} \mathrm{O}_{3}$, и меньше, чем $\mathrm{Sb}_{2} \mathrm{O}_{3}$. При увеличении количества $\mathrm{PbO}$ в композиции с 40 до 80 мол. \% его содержание в пленке возрастает примерно во столько же раз (2.5 раза). Для $\mathrm{Sb}_{2} \mathrm{O}_{3}$ эта зависимость выражена еще более ярко - содержа- ние сурьмы увеличивается в 15 раз при переходе от композиции $20 \% \mathrm{Sb}_{2} \mathrm{O}_{3}+80 \% \mathrm{PbO}$ к композиции $60 \% \mathrm{Sb}_{2} \mathrm{O}_{3}+40 \% \mathrm{PbO}$, что связано с относительно высоким давлением пара $\mathrm{Sb}_{2} \mathrm{O}_{3}$.

Поскольку при совместном испарении оксидов их содержание в пленке больше, чем при раздельном, то, следовательно, испарение хемостимуляторов из единой композиции протекает легче, чем их собственное испарение, и это приводит к положительному вкладу твердофазных взаимодействий между оксидами в суммарное отклонение от аддитивности.

Зависимости $d^{R}$ от состава композиций оксидов-хемостимуляторов $\mathrm{PbO}+\mathrm{MnO}_{2}$ и $\mathrm{V}_{2} \mathrm{O}_{5}+$ $\mathrm{MnO}_{2}$ (рис. 14) при пространственном разделении качественно совпадают с рассмотренными выше (композиции оксид $p$-элемента+оксид $d$ элемента и оксид $d$-элемента+оксид $d$-элемента (см. табл. 1).). Вклад твердофазных взаимодействий положителен и значителен по абсолютной величине, что, учитывая положительный знак эффекта, связано с превращением $\mathrm{PbO} \rightarrow \mathrm{Pb}_{3} \mathrm{O}_{4} \rightarrow$ $\mathrm{PbO}_{2}$ (появление в системе сильного, хотя и термически нестабильного окислителя), чему способствует зафиксированный переход $\mathrm{MnO}_{2} \rightarrow$ $\mathrm{Mn}_{3} \mathrm{O}_{4}$ (данные РФА). В композициях же с оксидами р-элементов $\left(\mathrm{Sb}_{2} \mathrm{O}_{3}\right.$ и $\left.\mathrm{Bi}_{2} \mathrm{O}_{3}\right)$ окисления оксида свинца (II) до (IV) не происходит и положи-

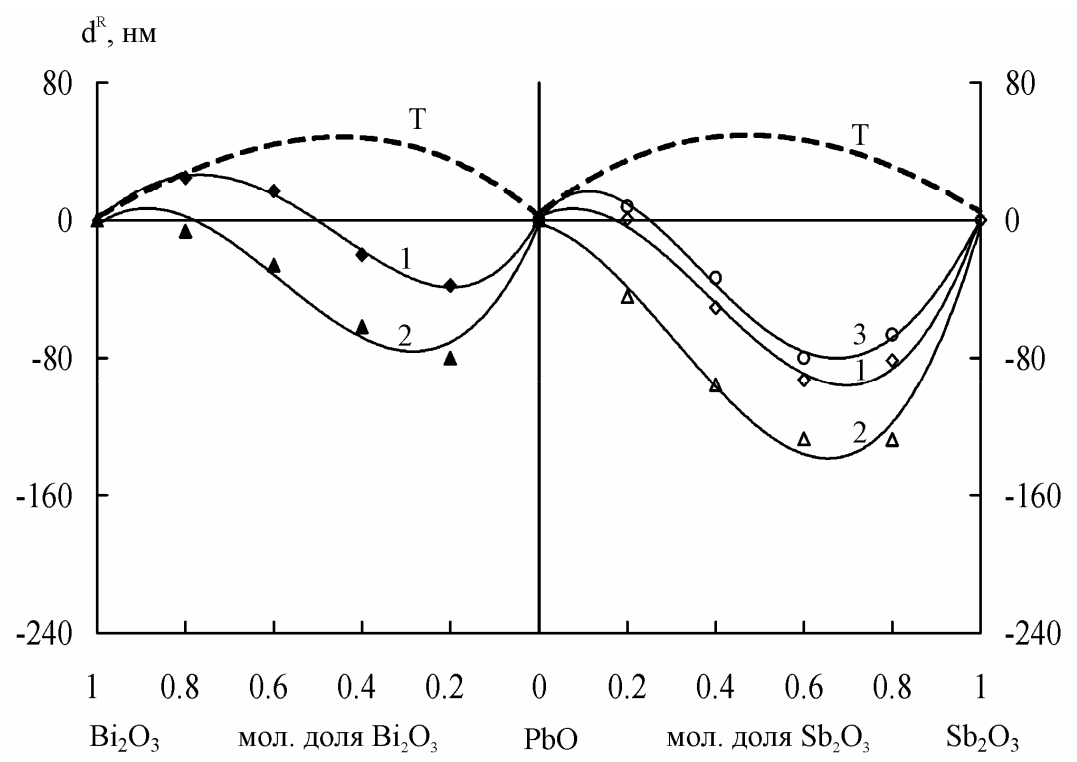

Рис. 13. Концентрационные зависимости $d^{R}$ оксидной пленки на GaAs; температура - $530{ }^{\circ} \mathrm{C}$, время - 40 мин: 1 - совместное воздействие; 2 - пространственное разделение; Т - рассчитанный вклад твердофазных взаимодействий

[Fig. 13. Concentration dependences of $d^{R}$ of the oxide film on GaAs; temperature- $530{ }^{\circ} \mathrm{C}$, time -40 min: 1 - mixture evaporation experiment, 2 - separate evaporations experiment, and T - calculated contribution from the gas-phase interaction between the chemostimulators] 


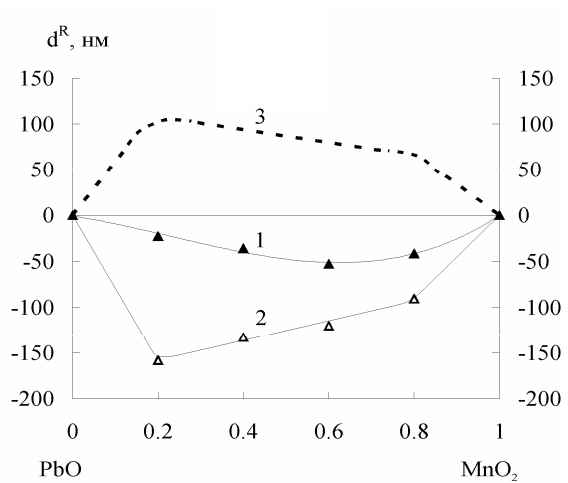

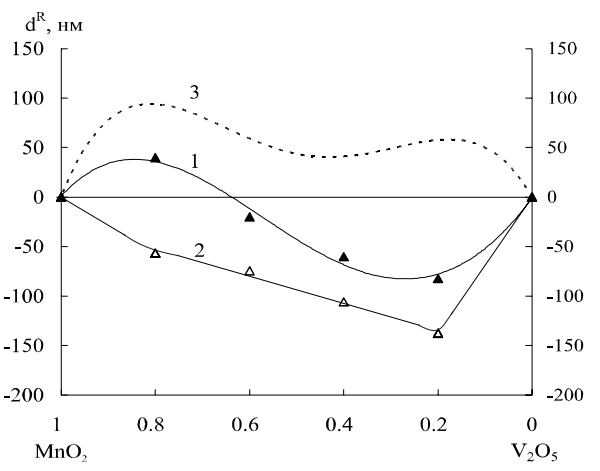

Рис. 14. Зависимости $d^{R}$ оксидной пленки на GaAs от состава композиции оксидов при температуре $560{ }^{\circ} \mathrm{C}$, время 40 мин: 1 - совместное воздействие; 2 - пространственное разделение; 3 - рассчитанный вклад твердофазных взаимодействий. $\mathrm{a}-$ композиция $\mathrm{PbO}+\mathrm{MnO}_{2}, \mathrm{~b}-\mathrm{V}_{2} \mathrm{O}_{5}+\mathrm{MnO}_{2}$

[Fig. 14. Dependence of $d^{R}$ of the oxide film on GaAs on the composition of oxides at a temperature of $560{ }^{\circ} \mathrm{C}$, time 40 min: 1 - mixture evaporation experiment, 2 - separate evaporations experiment, and $\mathrm{T}$ - calculated contribution from the gas-phase interaction between the chemostimulators: $a$ - composition $\left.\mathrm{PbO}+\mathrm{MnO}_{2}, b-\mathrm{V}_{2} \mathrm{O}_{5}+\mathrm{MnO}_{2}\right]$

тельный вклад твердофазных взаимодействий существенно снижен.

Ответственным за характер суммарного нелинейного эффекта воздействия $\mathrm{PbO}+\mathrm{MnO}_{2}$ (отрицательное отклонение во всем интервале составов композиции оксидов-хемостимуляторов) является взаимное влияние оксидов друг на друга в паровой фазе, отрицательное по знаку и перекрывающее положительный вклад твердофазных взаимодействий.

Содержание хемостимуляторов в пленке слабо зависит от соотношения оксидов в композиции (данные ЛРСМА). При пространственном разделении хемостимуляторов не только уменьшается их содержание в пленке по сравнению с совместным введением (от 3 раз для марганца до 6 раз для свинца), но и изменяется соотношение их концентраций. Если при пространственном разделении соотношение хемостимуляторов в пленке практически не зависит от состава композиции и составляет 0.05 ат. \% Mn к 0.06-0.07 ат. \% Рb, или 43.5 отн. \% $\mathrm{Mn}+56.5$ отн. \% Pb, то при испарении оксидов из единой композиции соотношение хемостимуляторов меняется от 17.3 отн. \% $\mathrm{Mn}+82.7$ отн. \% $\mathrm{Pb}$ для композиции 20.\% $\mathrm{MnO}_{2}+80 . \% \mathrm{PbO}$ (что примерно соответствует соотношению хемостимуляторов в навеске) до 30.4 отн. \% $\mathrm{Mn}+69.6$ отн. \% $\mathrm{Pb}$ для композиции $80 \% \mathrm{MnO}_{2}+20 \% \mathrm{PbO}$.

С увеличением содержания в композиции данного оксида соответственно растет его количество и в полученной оксидной пленке. При раздельном испарении оно существенного меньше по сравне- нию с испарением из единой композиции того же состава: для $\mathrm{MnO}_{2}$ - от 2 до 3 раз, а для $\mathrm{V}_{2} \mathrm{O}_{5}$ - около 3 раз. Такая тенденция сохранения соотношения хемостимуляторов в навеске и в оксидной пленке имеет место и при оксидировании GaAs c пространственным разделением хемостимуляторов. Для композиции состава $80 \% \mathrm{~V}_{2} \mathrm{O}_{5}+20 \% \mathrm{MnO}_{2}$ в оксидной пленке на поверхности GaAs обнаружено 0.26 ат. \% V и 0.05 aт. \% Mn, т. е. их соотношение составило 83.8 отн. \% V +16.2 отн. \% Mn, а для композиции $20 \% \mathrm{~V}_{2} \mathrm{O}_{5}+80 \% \mathrm{MnO}_{2}-0.08$ aт. $\% \mathrm{~V}$ и 0.30 ат. \% Мn или 21.1 отн. \% V+78.9 отн. \% Mn. При определении относительных процентов хемостимуляторов в пленке их общее количество принималось за 100 \%, а затем индивидуальное содержание каждого делилось на эту величину. Совместное испарение оксидов-хемостимуляторов способствует их внедрению в растущую на поверхности GaAs оксидную пленку, интенсифицируя транзитные взаимодействия, что и приводит к ее большей толщине и уменьшению отрицательного отклонение от аддитивности. Именно в этом и заключается положительный вклад твердофазных взаимодействий в суммарный нелинейный эффект.

На рис. 15 представлены результаты термооксидирования GaAs под воздействием композиций $\mathrm{PbO}+\mathrm{MnO}$ при их совместном испарении и пространственном разделении. Общий характер нелинейных зависимостей, полученных при пространственном разделении хемостимуляторов, для композиции $\mathrm{PbO}+\mathrm{MnO}$, в очень незначительной степени отличается от такового, выявленного при испа- 
рении из единой композиции. Как следствие этого, вклад твердофазных взаимодействий в суммарный нелинейный эффект оказывается также весьма незначительным (кривая 3 на рис. 15). Зависимость этого вклада, как от состава композиции активаторов, так и от температуры процесса весьма слабая. При этом по знаку вклад твердофазных взаимодействий является положительным.

Следовательно, основную ответственность за суммарный нелинейный эффект несет взаимное влияние активаторов в паровой фазе, которое является отрицательным по знаку и существенно перекрывает незначительный положительный вклад твердофазных взаимодействий. Из приведенных зависимостей отчетливо прослеживается зависимость вклада твердофазных взаимодействий от степени окисления одного из оксидов, входящих в состав композиции, а именно $\mathrm{MnO}_{2}$ и $\mathrm{MnO}$. Оксид марганца (IV) претерпевает при нагревании более существенные химические превращения [33], чем оксид марганца (II). Отсюда и следует более существенный вклад твердофазных взаимодействий в композициях с его участием и более ярко выраженные нелинейные эффекты при термическом оксидировании GaAs даже с пространственным разделением хемостимуляторов.

В случае термического окисидирования GaAs под воздействием композиций $\mathrm{PbO}+\mathrm{MnO}$ прослеживается зависимость содержания хемостимуляторов в пленке от состава композиции хемостимуляторов, чего ранее (в композициях с участием $\mathrm{MnO}_{2}$ ) не наблюдалось. Соотношение хемостимуляторов между собой в навеске и на поверхности GaAs не сохраняется: в навеске $20 \% \mathrm{PbO}+80 \%$ $\mathrm{MnO}$, в пленке -35.7 отн. \% $\mathrm{Pb}+64.3$ отн. \% Mn; в навеске $80 \% \mathrm{PbO}+20 \% \mathrm{MnO}$, в пленке - 70 отн. $\% \mathrm{~Pb}+30$ отн. \% Mn. При уменьшении содержания в композиции $\mathrm{MnO}$ в четыре раза его абсолютное содержание в пленке падает только на $30 \%$, а относительное - в два раза. Повышенное содержание в пленках марганца по сравнению с оксидированием под воздействием композиции с участием $\mathrm{MnO}_{2}$ того же состава, в принципе, согласуется с литературными данными об испарении этих оксидов $\left(\mathrm{MnO}_{2}\right.$ испаряется, преимущественно отщепляя кислород, a $\mathrm{MnO}$ - не только с диссоциацией, но и в виде молекул [31]). В то же время $\mathrm{MnO}$ является слабым хемостимулятором (малые значения толщины оксидного слоя при его индивидуальном воздействии) и его повышенное содержание в оксидных слоях приводит к отрицательному отклонению от аддитивности. При испарении $\mathrm{PbO}$

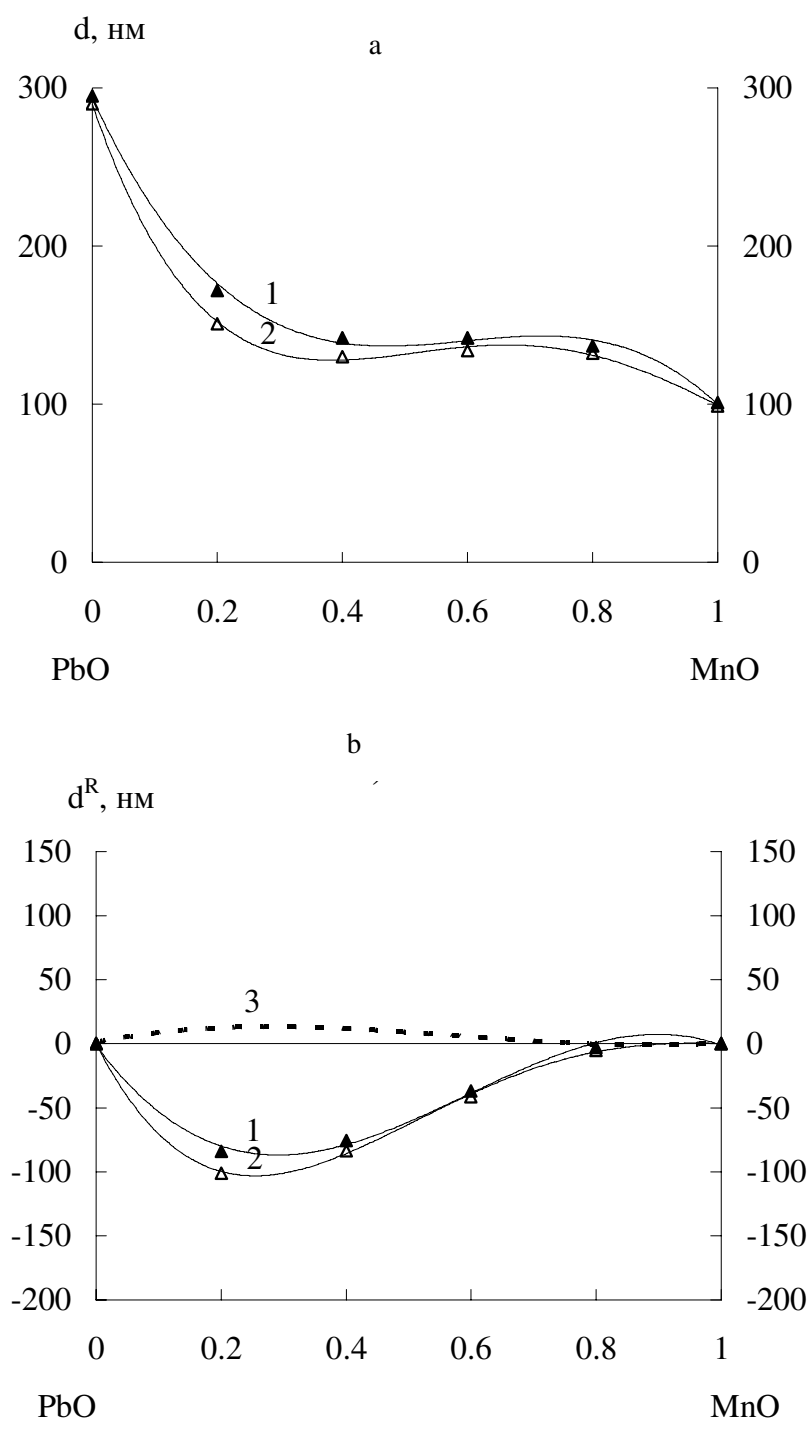

Рис. 15. Зависимости толщины оксидной пленки (a) и относительной интегральной толщины $(b)$ на $\mathrm{GaAs}$ от состава композиции оксидов $\mathrm{PbO}+\mathrm{MnO}$ при $560{ }^{\circ} \mathrm{C}$, время 40 мин: 1 - совместное воздействие; 2 - пространственное разделение; 3 - рассчитанный вклад твердофазных взаимодействий

[Fig. 15. Dependence of the oxide film thickness $(a)$ and relative integral thickness $(b)$ on $\mathrm{GaAs}$ on the composition of $\mathrm{PbO}+\mathrm{MnO}$ oxides at $560{ }^{\circ} \mathrm{C}$, time $40 \mathrm{~min}$ : 1 - mixture evaporation experiment, 2 - separate evaporations experiment, and $\mathrm{T}$ - calculated contribution from the gasphase interaction between the chemostimulators]

и $\mathrm{MnO}$ из единой композиции состава $80 \% \mathrm{PbO}+$ $20 \% \mathrm{MnO}$ содержание их в пленке практически не меняется и составляет 83.9 отн. \% $\mathrm{Pb}+16.1$ отн. $\% \mathrm{Mn}$. Следовательно, при совместном испарении включение $\mathrm{PbO}$ в оксидный слой происходит предпочтительно по сравнению с раздельным испарением. Поскольку он является более активным хемостимулятором, нежели $\mathrm{MnO}$, то его увеличенное 
содержание в оксидных пленках на поверхности GaAs при совместном испарении по сравнению с раздельным и можно трактовать как положительный вклад твердофазных взаимодействий в суммарный отрицательный нелинейный эффект воздействия композиций $\mathrm{PbO}+\mathrm{MnO}$ на процесс термического оксидирования GaAs.

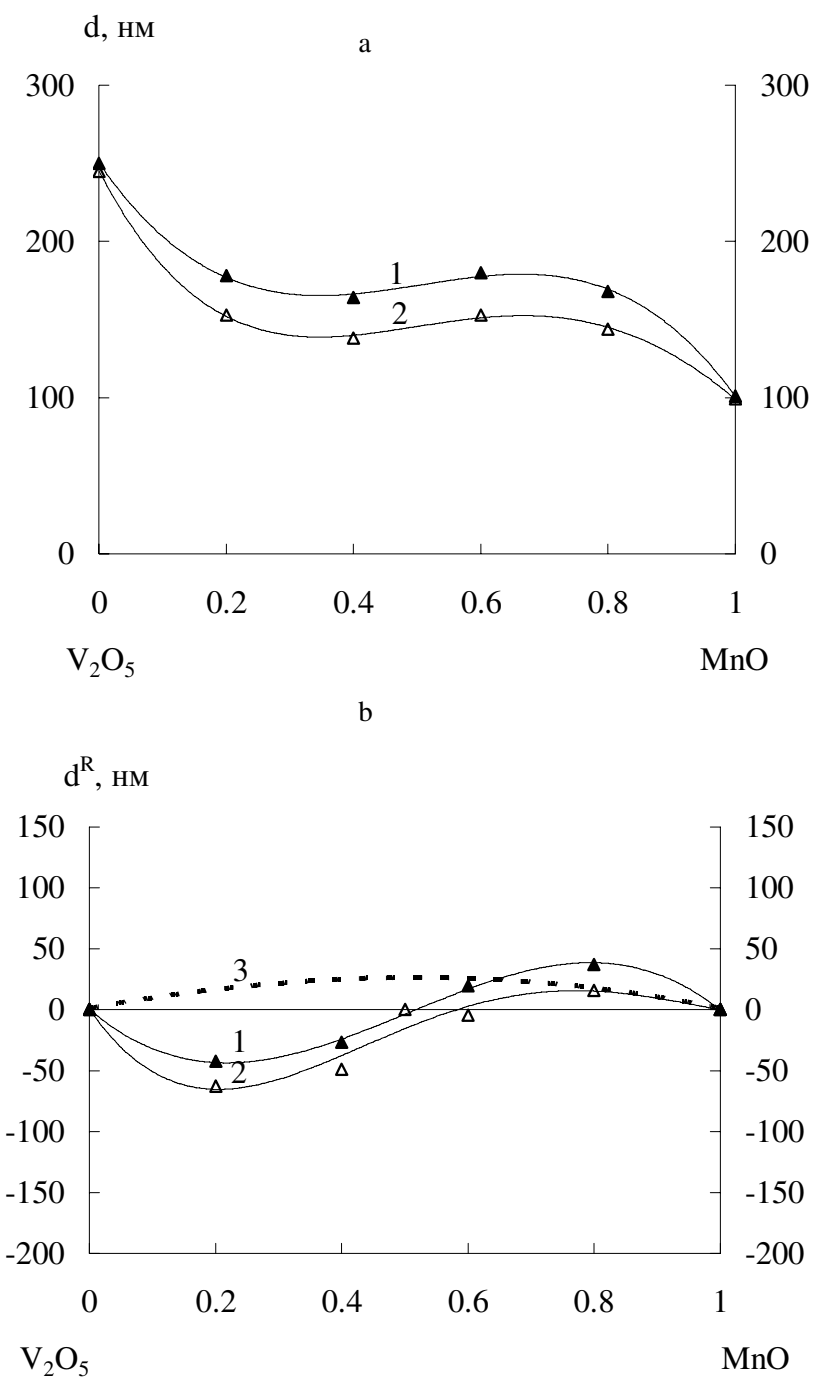

Рис. 16. Зависимости толщины оксидной пленки $(a)$ и относительной интегральной толщины (b) на GaAs от состава композиции оксидов $\mathrm{V}_{2} \mathrm{O}_{5}+\mathrm{MnO}$ при $560{ }^{\circ} \mathrm{C}$, время 40 мин: 1 - совместное воздействие; 2 - пространственное разделение; 3 - рассчитанный вклад твердофазных взаимодействий

[Fig. 16. Dependence of the thickness of the oxide film (a) and relative integrated thickness $(b)$ on $\mathrm{GaAs}$ from the composition of the oxides $\mathrm{V}_{2} \mathrm{O}_{5}+\mathrm{MnO}$ at $560{ }^{\circ} \mathrm{C}$, time 40 min: 1 - mixture evaporation experiment, 2 - separate evaporations experiment, and - calculated contribution from the gas-phase interaction between the chemostimulators]
Результаты термооксидирования $\mathrm{GaAs}$ под воздействием композиций $\mathrm{V}_{2} \mathrm{O}_{5}+\mathrm{MnO}$ (два оксида $d$-элемента, см. табл. 1) при их пространственном разделении, а также вклада твердофазных взаимодействий в общий нелинейный эффект (рис. 16b) показывают большее сходство с зависимостями, полученными для термического оксидирования $\mathrm{GaAs}$ под воздействием композиций $\mathrm{PbO}+\mathrm{MnO}$, и существенно отличаются от таковых для термооксидирования GaAs под воздействием композиций $\mathrm{V}_{2} \mathrm{O}_{5}+\mathrm{MnO}_{2}$. Вклад твердофазных взаимодействий в суммарный нелинейный эффект является положительным по знаку, весьма незначителен по абсолютной величине и очень мало меняется с ростом температуры оксидирования.

Содержание хемостимуляторов в оксидной пленке на поверхности GaAs закономерно изменяется от состава композиции, под воздействием которой проходило оксидирование. Если в композициях соотношение меняется от 4:1 до 1:4 как для одного, так и для другого оксида, то в пленке на поверхности $\mathrm{GaAs}$ соотношение составляет от 62.5 отн. \% V + 37.5 отн. \% Mn, до 31.8 отн. \% V + 69.2 отн. \% Mn. В то же время при совместном испарении соотношение компонентов в оксидной пленке, полученной под действием композиций тех же составов, остаемся практически постоянным 1.61.7:1. Такое изменение режима испарения хемостимуляторов из единой композиции, очевидно, и является отражением наличия вклада твердофазных взаимодействий в суммарный нелинейный эффект зависимости толщины оксидной пленки на GaAs от состава композиции $\mathrm{V}_{2} \mathrm{O}_{5}+\mathrm{MnO}$.

Таким образом, взаимодействия между оксидами-хемостимуляторами, ответственные за установленные нелинейные эффекты, локализованы в твердой (композиция оксидов) и газовой фазах. При этом для большинства композиций вклад твердофазных взаимодействий положителен, а вклад взаимодействий в газовой фазе отрицателен и усилен по абсолютной величине. Во всех случаях, когда между компонентами-хемостимуляторами реализуются взаимодействия в твердой фазе (при их совместном введении), они стабилизируют в паровой фазе молекулярные оксидные формы хемостимулятора, обеспечивая тем самым положительный эффект. Если химические взаимодействия между компонентами отсутствуют (например, композиция $\mathrm{Sb}_{2} \mathrm{O}_{3}+\mathrm{Bi}_{2} \mathrm{O}_{3}$ ), то и в газовой фазе никаких дополнительных взаимодействий, кроме диссоциативных, не наблюдается. Если же взаимодействия в твердой фазе возможны, но не очень ярко выраже- 
ны (система $\mathrm{PbO}+\mathrm{Bi}_{2} \mathrm{O}_{3}$ ), то реализуется промежуточный вариант. Дополнительные агрегаты в паре не образуются, диссоциативные процессы преобладают, но сам процесс испарения стимулируется, общее давление пара несколько увеличивается.

\section{ВОЗДЕЙСТВИЕ НА ТЕРМООКСИДИРОВАНИЕ GaAs КОМПОЗИЦИЙ ОКСИДОВ С УЧАСТИЕМ ИНЕРТНОГО КОМПОНЕНТА}

Из рассмотренных вариантов взаимоотношений хемостимуляторов и оксидируемой полупроводниковой подложки (см. рис. 2) помимо варианта $(a)$ наиболее реализуемым является вариант $(d)$. Для его достижения необходимо, чтобы один из оксидов композиции был неспособен передавать кислород компонентам подложки (фактически не являлся хемостимулятором) и был достаточно химически инертным, чтобы не взаимодействовать с оксидом-хемостимулятором композиции. В случае полупроводника GaAs очевидным оксидом, не проявляющим хемостимулирующие свойства, является $\mathrm{Ga}_{2} \mathrm{O}_{3}$, поскольку именно он термодинамически наиболее стабилен и образуется в процессе собственного термооксидирования GaAs. B качестве второго компонента композиции могут выступать такие хорошо исследованные хемостимуляторы, как $\mathrm{Sb}_{2} \mathrm{O}_{3}, \mathrm{Bi}_{2} \mathrm{O}_{3}, \mathrm{MnO}, \mathrm{MnO}_{2}$.

Полученные в работах [32-38] зависимости толщины оксидной пленки на поверхности GaAs от состава композиции оксид-хемостимулятор+инертный компонент (для перечисленных выше оксидов) представлены на рис. 17-19.

Для композиции $\mathrm{Sb}_{2} \mathrm{O}_{3}+\mathrm{Ga}_{2} \mathrm{O}_{3}$ максимальное отрицательное отклонение от аддитивности имеет место в области малых концентраций (10 мол. \%) $\mathrm{Ga}_{2} \mathrm{O}_{3}$ (рис. 17a). При дальнейшем увеличении его содержания в композиции это отрицательное откло-
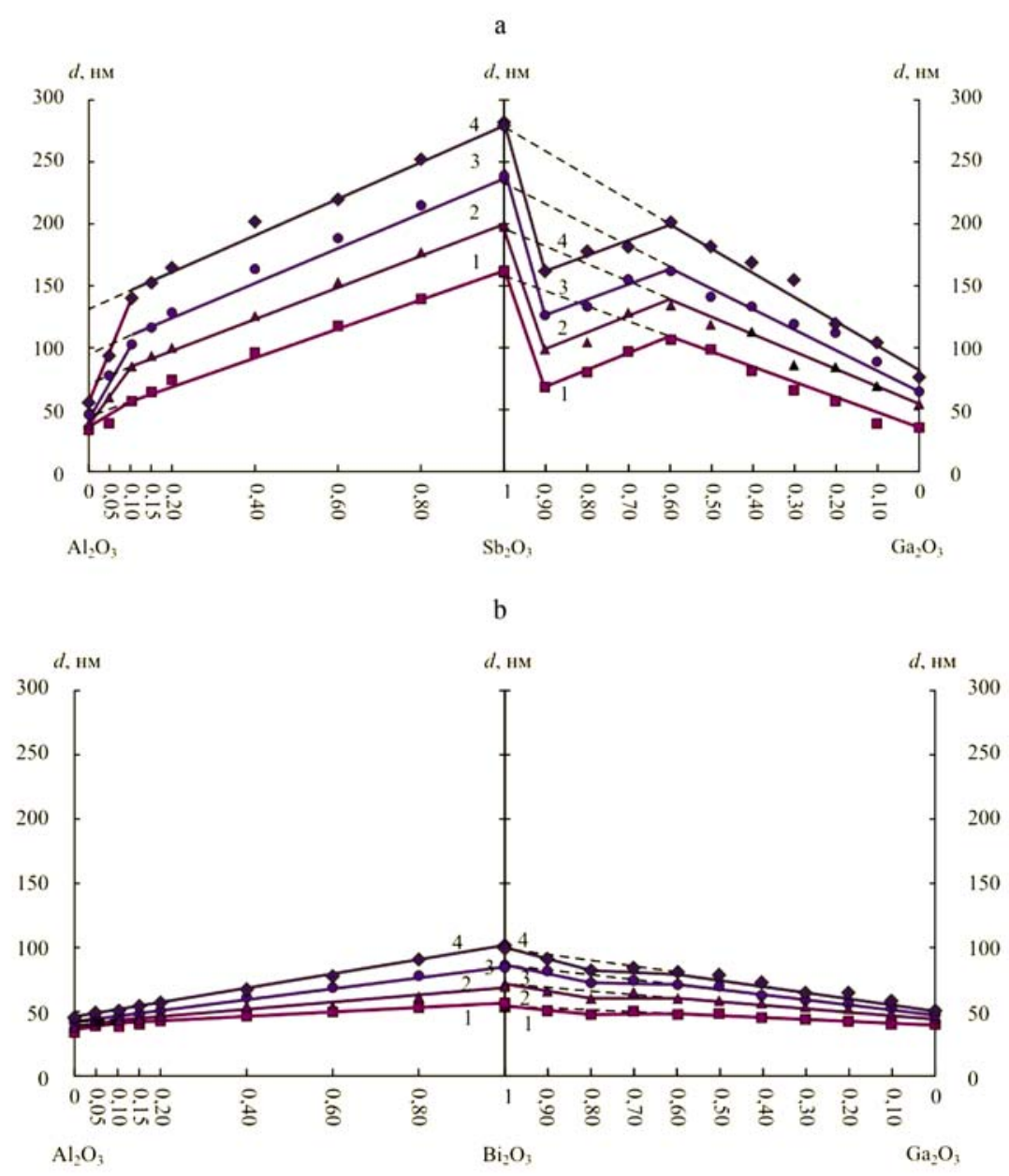

Рис. 17. Зависимость толщины $d$ оксидной пленки на $\mathrm{GaAs}$ от состава композиций $\mathrm{Sb}_{2} \mathrm{O}_{3}(a)$ и $\mathrm{Bi}_{2} \mathrm{O}_{3}(b)$ с инертными компонентами $\mathrm{Ga}_{2} \mathrm{O}_{3}$ и $\mathrm{Al}_{2} \mathrm{O}_{3}$ при $530^{\circ} \mathrm{C}$ и продолжительности оксидирования: 1 - 10;2 - 20; 3 - 30; 4 - 40 минут

[Fig. 17. Dependence of the thickness d of the oxide film on GaAs on the composition of $\mathrm{Sb}_{2} \mathrm{O}_{3}(a)$ and $\mathrm{Bi}_{2} \mathrm{O}_{3}(b)$ compositions with inert components $\mathrm{Ga}_{2} \mathrm{O}_{3}$ and $\mathrm{Al}_{2} \mathrm{O}_{3}$ at $530{ }^{\circ} \mathrm{C}$ and oxidation times: $1-10 ; 2-20 ; 3-30 ; 4-40$ min] 


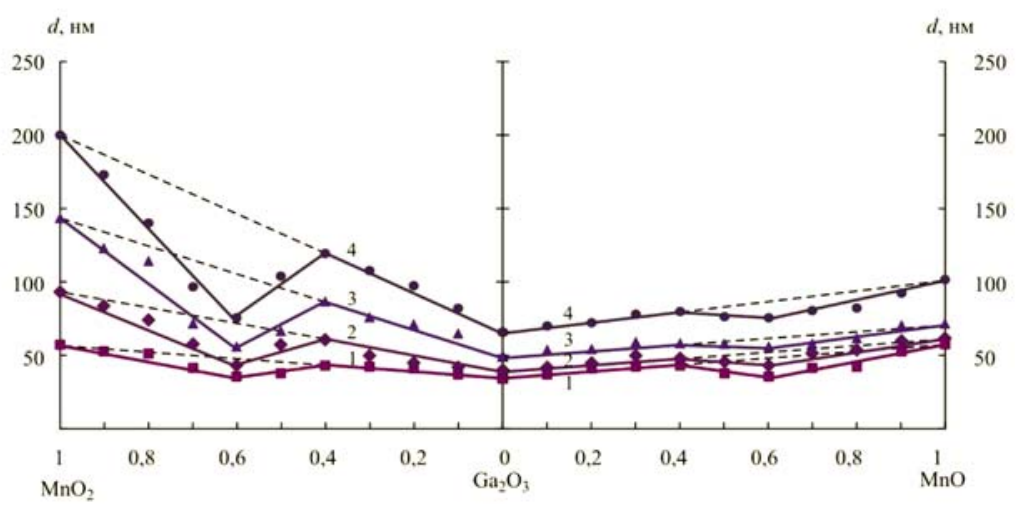

b

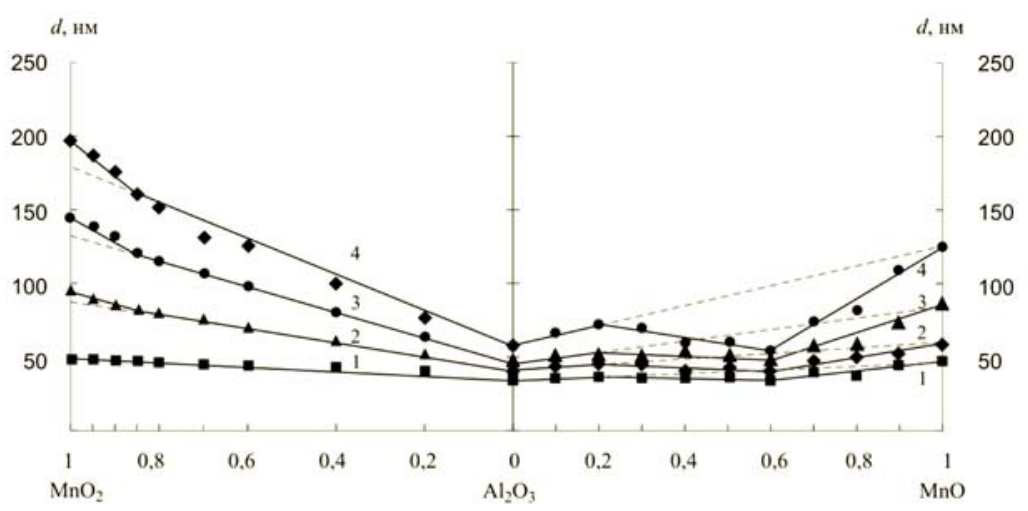

Рис. 18. Зависимость толщины $d$ оксидной пленки на GaAs от состава композиций $\mathrm{MnO}_{2}$ и $\mathrm{MnO}$ с инертными компонентами $\mathrm{Ga}_{2} \mathrm{O}_{3}(a)$ и $\mathrm{Al}_{2} \mathrm{O}_{3}(b)$ при $530{ }^{\circ} \mathrm{C}$ и продолжительности оксидирования: 1 - $10 ; 2-20 ; 3$ - 30; 4 40 минут

[Fig. 18. Dependence of the oxide film thickness d on GaAs on the composition of $\mathrm{MnO}_{2}$ and $\mathrm{MnO}$ compositions with inert components $\mathrm{Ga}_{2} \mathrm{O}_{3}(a)$ and $\mathrm{Al}_{2} \mathrm{O}_{3}(b)$ at $530{ }^{\circ} \mathrm{C}$ and oxidation times: $\left.1-10 ; 2-20 ; 3-30 ; 4-40 \mathrm{~min}\right]$

нение уменьшается и, начиная с 40 мол. \% $\mathrm{Ga}_{2} \mathrm{O}_{3}$, наблюдается аддитивная зависимость. При этом точки на ординате $\mathrm{Ga}_{2} \mathrm{O}_{3}$ соответствуют собственному оксидированию GaAs. Экстраполяция аддитивных прямых к ординате $\mathrm{Sb}_{2} \mathrm{O}_{3}$ дает результаты, фактически совпадающие с данными для оксидирования GaAs при индивидуальном хемостимулирующем воздействии $\mathrm{Sb}_{2} \mathrm{O}_{3}$. Для композиции $\mathrm{Bi}_{2} \mathrm{O}_{3}+\mathrm{Ga}_{2} \mathrm{O}_{3}$ имеет место аналогичная картина - отрицательное отклонение от аддитивности при небольшом содержании (10-20 мол. \%) оксида галлия (рис. $17 b$ ), исчезающее при 40 мол. $\% \mathrm{Ga}_{2} \mathrm{O}_{3}$.

Процессы термооксидирования GaAs под воздействием композиций $\mathrm{MnO}_{2}$ и $\mathrm{MnO}$ с инертным компонентом $\mathrm{Ga}_{2} \mathrm{O}_{3}$ отражают иную ситуацию. Добавление $\mathrm{Ga}_{2} \mathrm{O}_{3}$ как к $\mathrm{MnO}_{2}$, так и к $\mathrm{MnO}$ сильно снижает темп прироста толщины оксидного слоя, тормозя хемостимулирующее действие оксида марганца (II), с минимумом в области $40 \% \mathrm{Ga}_{2} \mathrm{O}_{3}$ (рис. $18 a$ ). Дальнейшее увеличение содержания инертного ком- понента в композиции приводит к уменьшению отрицательного отклонения, и в области составов $100-60 \% \mathrm{Ga}_{2} \mathrm{O}_{3}$ отмечается линейная зависимость толщины оксидной пленки от состава композиции. При этом, по-прежнему, точки на ординате $\mathrm{Ga}_{2} \mathrm{O}_{3}$ coответствуют собственному оксидированию GaAs в отсутствие хемостимулятора в данных условиях, а экстраполяция линейного участка прямых к ординатам $\mathrm{MnO}_{2}$ и $\mathrm{MnO}$ дает результаты, совпадающие с данными для оксидирования GaAs при индивидуальном воздействии хемостимуляторов.

Таким образом, композиции с участием оксида галлия в качестве инертного компонента не в полной мере отвечают варианту $(d)$ на рис. 2, поскольку аддитивная зависимость толщины оксидной пленки на поверхности GaAs от состава композиции оксидов имеет место только в некотором интервале составов.

Альтернативными кандидатами на роль инертных компонентов выступают оксиды алюминия и 


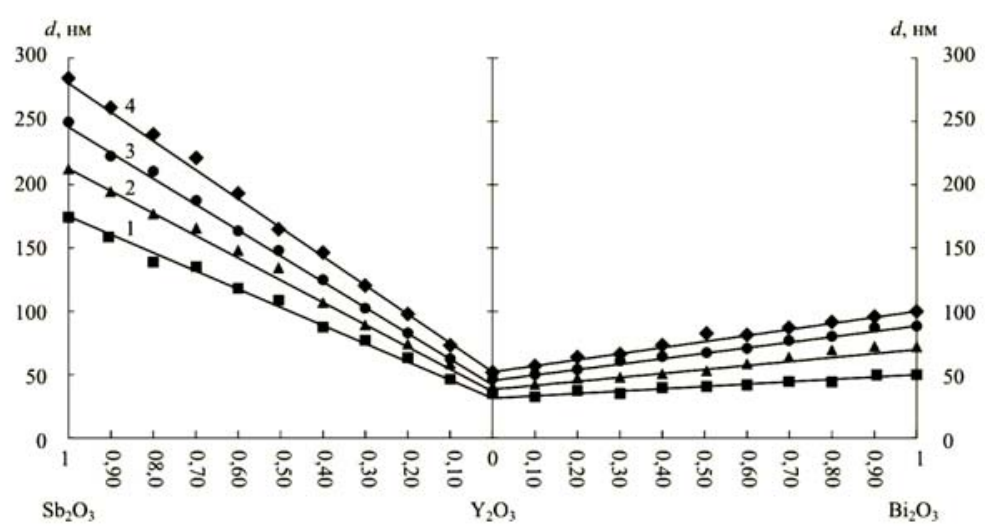

b

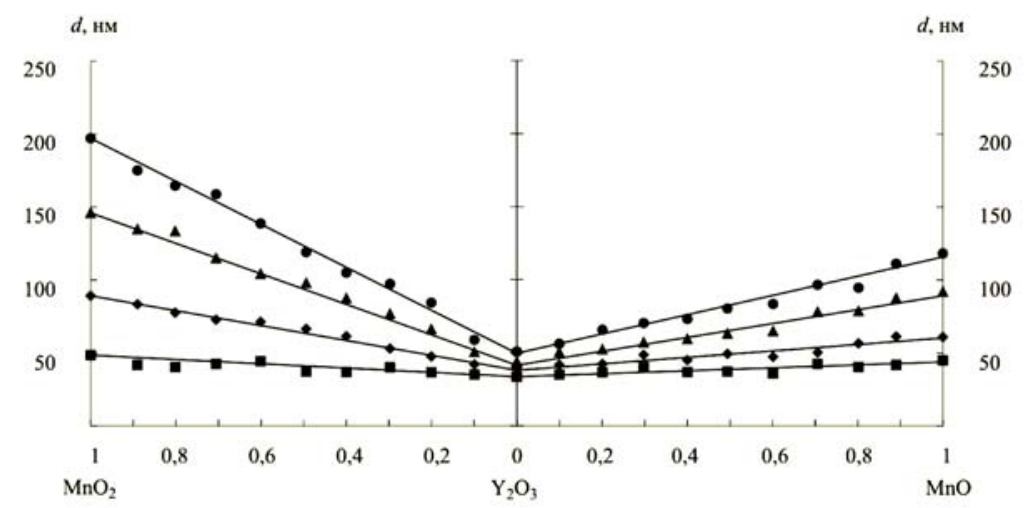

Рис. 19. Зависимость толщины $d$ оксидной пленки на GaAs от состава композиций инертного компонента $\mathrm{Y}_{2} \mathrm{O}_{3} \mathrm{c}$ оксидами-хемостимуляторами $\mathrm{Sb}_{2} \mathrm{O}_{3}$ и $\mathrm{Bi}_{2} \mathrm{O}_{3}(a), \mathrm{MnO}_{2}$ и $\mathrm{MnO}(b)$ при $530^{\circ} \mathrm{C}$ и продолжительности оксидирования: $1-10 ; 2-20 ; 3-30 ; 4-40$ минут

[Fig. 19. Dependence of the thickness $d$ of the oxide film on GaAs on the composition of the inert component $\mathrm{Y}_{2} \mathrm{O}_{3}$ with oxides-chemostimulators $\mathrm{Sb}_{2} \mathrm{O}_{3}$ and $\mathrm{Bi}_{2} \mathrm{O}_{3}(a), \mathrm{MnO}_{2}$ and $\mathrm{MnO}(b)$ at $530^{\circ} \mathrm{C}$ and oxidation times: $1-10,2-20,3-30$, $4-40 \mathrm{~min}]$

иттрия. Хотя они и не являются продуктами оксидирования поверхности подложки, тем не менее, они также не способны вступать в реакции транзитного взаимодействия и химически не взаимодействуют со вторым компонентом оксидной композиции (оксидом-хемостимулятором).

Для зависимостей, полученных под воздействием композиций $\mathrm{Al}_{2} \mathrm{O}_{3}+\mathrm{Sb}_{2} \mathrm{O}_{3}$ (рис. 17a), можно выделить линейный участок в пределах 10-100 мол. $\% \mathrm{Sb}_{2} \mathrm{O}_{3}$, т. е. на основном протяжении оси составов. Однако экстраполяция прямых (1-4) к ординате $\mathrm{Al}_{2} \mathrm{O}_{3}$ (пунктир на рис. 17a) дает завышенные значения толщины оксидной пленки по сравнению с собственным оксидированием GaAs в аналогичных условиях. Для процесса оксидирования арсенида галлия под воздействием композиций $\mathrm{Al}_{2} \mathrm{O}_{3}+\mathrm{Bi}_{2} \mathrm{O}_{3}$ (рис. 17b) в интервале времени 10-20 минут на протяжении составов 10-100 $\% \mathrm{Bi}_{2} \mathrm{O}_{3}$ также имеет место линейная зависимость толщины оксидного слоя от состава композиции.
Опять-таки, как и в предыдущем случае, экстраполяция линейной зависимости к ординате $\mathrm{Al}_{2} \mathrm{O}_{3}$ дает несколько завышенные значения толщины оксидной пленки по сравнению с собственным оксидированием GaAs. На развитой же стадии процесса (время 30-40 мин) аддитивность наблюдается во всем концентрационном интервале композиций $\mathrm{Al}_{2} \mathrm{O}_{3}+\mathrm{Bi}_{2} \mathrm{O}_{3}$.

Для композиции с участием $\mathrm{MnO}_{2}$ (рис. $18 a$ ) линейная зависимость сохраняется от чистого оксида алюминия (что аналогично собственному оксидированию) до 80 мол. \% $\mathrm{MnO}_{2}$, а экстраполяция к ординате диоксида марганца дает заниженные значения толщины по сравнению с оксидированием при индивидуальном хемостимулирующем воздействии $\mathrm{MnO}_{2}$. При этом для малого времени (кривая 1) аддитивность наблюдается во всем интервале составов, а с увеличением времени процесса отрицательное отклонение от аддитивности выражено все интенсивнее. 
Зависимость толщины оксидной пленки на поверхности GaAs от состава для композиций $\mathrm{MnO}+\mathrm{Al}_{2} \mathrm{O}_{3}$ (рис. $18 b$ ) в небольшом интервале составов является линейной, однако при добавлении инертного компонента к $\mathrm{MnO}$ происходит ослабление хемостимулирующего действия оксида марганца (II), и в области $60 \% \mathrm{Al}_{2} \mathrm{O}_{3}$ имеет место отклонение от аддитивной прямой. При увеличении содержания $\mathrm{Al}_{2} \mathrm{O}_{3}$ в композиции это отрицательное отклонение уменьшается и, начиная с 20 мол. \% $\mathrm{Al}_{2} \mathrm{O}_{3}$, зависимость становится аддитивной.

Для процессов оксидирования арсенида галлия под воздействием композиций $\mathrm{Y}_{2} \mathrm{O}_{3}+\mathrm{Sb}_{2} \mathrm{O}_{3}$, $\mathrm{Y}_{2} \mathrm{O}_{3}+\mathrm{Bi}_{2} \mathrm{O}_{3}, \mathrm{Y}_{2} \mathrm{O}_{3}+\mathrm{MnO}$ и $\mathrm{Y}_{2} \mathrm{O}_{3}+\mathrm{MnO}_{2}$ экспериментально получена аддитивная линейная зависимость во всем концентрационном интервале составов (рис. 19). При этом точки на ординате $\mathrm{Y}_{2} \mathrm{O}_{3}$ соответствуют собственному оксидированию GaAs в отсутствие хемостимулятора, т. е. действительно наблюдается аддитивная зависимость толщины оксидной пленки на поверхности GaAs от состава композиции инертный компонент+оксид-хемостимулятор. Следовательно, из трех оксидов-инертных компонентов только в случае композиций с участи- ем оксида иттрия действительно реализуется вариант $(d)$ схемы, представленной на рис. 2.

Поскольку и $\mathrm{Ga}_{2} \mathrm{O}_{3}$, и $\mathrm{Al}_{2} \mathrm{O}_{3}$ являются химически инертными по отношению к оксидам-хемостимуляторам, то, очевидно, причины отклонений от аддитивности следует отнести к нехимическому взаимному влиянию оксидов друг на друга. В качестве таких нехимических факторов могут выступать процессы спекания, влияющие на динамику испарения оксидов и эффективность их хемостимулирующего воздействия.

Определение площади удельной поверхности порошковых композиций и их компонентов (табл. 2) методом тепловой десорбции азота показало, что в области отрицательного отклонения происходит резкое снижение удельной поверхности; при отжиге композиций $\mathrm{Ga}_{2} \mathrm{O}_{3}+$ хемостимулятор в 1.7-6 раз по сравнению с исходной композицией. Для линейного интервала изменение удельной поверхности не столь значительно ( в 1.11.2 раза).

В области отрицательного отклонения (6080 мол. \% хемостимулятора) для композиций оксида марганца (II) с $\mathrm{Al}_{2} \mathrm{O}_{3}$, аналогично системам

Таблица 2. Результаты исследования удельной поверхности композиций с инертными компонентами и индивидуальных оксидов методом БЭТ

[Table 2. Results of the study of the specific surface of compositions with inert components and individual oxides by the BET method]

\begin{tabular}{|c|c|c|c|c|c|}
\hline $\begin{array}{c}\text { Образец } \\
\text { [Sample] }\end{array}$ & $S_{\text {yд }}^{0}, \mathrm{~m}^{2} / \mathrm{g}$ & $S_{\mathrm{yA}}^{1}, \mathrm{~m}^{2} / \mathrm{g}$ & $\begin{array}{c}\text { Образец } \\
\text { [Sample] }\end{array}$ & $S_{\text {уд }}^{0}, \mathrm{~m}^{2} / \mathrm{g}$ & $S_{\mathrm{yA}}^{1}, \mathrm{~m}^{2} / \mathrm{g}$ \\
\hline $\mathrm{Ga}_{2} \mathrm{O}_{3}$ & 8.68 & 8.66 & $\left(\mathrm{Al}_{2} \mathrm{O}_{3}\right)_{0.8}\left(\mathrm{Bi}_{2} \mathrm{O}_{3}\right)_{0.2}$ & 65.88 & 64.53 \\
\hline $\mathrm{Al}_{2} \mathrm{O}_{3}$ & 105.25 & 104.51 & $\left(\mathrm{Y}_{2} \mathrm{O}_{3}\right)_{0.2}\left(\mathrm{Bi}_{2} \mathrm{O}_{3}\right)_{0.8}$ & 5.54 & 4.54 \\
\hline $\mathrm{Y}_{2} \mathrm{O}_{3}$ & 9.14 & 9.13 & $\left(\mathrm{Y}_{2} \mathrm{O}_{3}\right)_{0.8}\left(\mathrm{Bi}_{2} \mathrm{O}_{3}\right)_{0.2}$ & 9.88 & 9.03 \\
\hline $\mathrm{Sb}_{2} \mathrm{O}_{3}$ & 0.78 & 0.94 & $\left(\mathrm{Ga}_{2} \mathrm{O}_{3}\right)_{0.4}\left(\mathrm{MnO}_{2}\right)_{0.6}$ & 9.01 & 4.50 \\
\hline $\mathrm{Bi}_{2} \mathrm{O}_{3}$ & 0.94 & 0.93 & $\left(\mathrm{Ga}_{2} \mathrm{O}_{3}\right)_{0.8}\left(\mathrm{MnO}_{2}\right)_{0.2}$ & 8.85 & 8.67 \\
\hline $\mathrm{MnO}$ & 5.94 & 5.81 & $\left(\mathrm{Al}_{2} \mathrm{O}_{3}\right)_{0.2}\left(\mathrm{MnO}_{2}\right)_{0.8}$ & 74.48 & 74.14 \\
\hline $\mathrm{MnO}_{2}$ & 10.78 & 10.75 & $\left(\mathrm{Al}_{2} \mathrm{O}_{3}\right)_{0.8}\left(\mathrm{MnO}_{2}\right)_{0.2}$ & 29.89 & 25.56 \\
\hline$\left(\mathrm{Ga}_{2} \mathrm{O}_{3}\right)_{0.2}\left(\mathrm{Sb}_{2} \mathrm{O}_{3}\right)_{0.8}$ & 7.62 & 1.27 & $\left(\mathrm{Y}_{2} \mathrm{O}_{3}\right)_{0.2}\left(\mathrm{MnO}_{2}\right)_{0.8}$ & 10.58 & 10.34 \\
\hline$\left(\mathrm{Ga}_{2} \mathrm{O}_{3}\right)_{0.8}\left(\mathrm{Sb}_{2} \mathrm{O}_{3}\right)_{0.2}$ & 6.93 & 5.55 & $\left(\mathrm{Y}_{2} \mathrm{O}_{3}\right)_{0.8}\left(\mathrm{MnO}_{2}\right)_{0.2}$ & 9.98 & 9.75 \\
\hline$\left(\mathrm{Al}_{2} \mathrm{O}_{3}\right)_{0.2}\left(\mathrm{Sb}_{2} \mathrm{O}_{3}\right)_{0.8}$ & 19.37 & 18.94 & $\left(\mathrm{Ga}_{2} \mathrm{O}_{3}\right)_{0.4}(\mathrm{MnO})_{0.6}$ & 5.26 & 2.27 \\
\hline$\left(\mathrm{Al}_{2} \mathrm{O}_{3}\right)_{0.8}\left(\mathrm{Sb}_{2} \mathrm{O}_{3}\right)_{0.2}$ & 64.09 & 64.16 & $\left(\mathrm{Ga}_{2} \mathrm{O}_{3}\right)_{0.8}(\mathrm{MnO})_{0.2}$ & 6.38 & 6.20 \\
\hline$\left(\mathrm{Y}_{2} \mathrm{O}_{3}\right)_{0.2}\left(\mathrm{Sb}_{2} \mathrm{O}_{3}\right)_{0.8}$ & 4.48 & 3.51 & $\left(\mathrm{Al}_{2} \mathrm{O}_{3}\right)_{0.4}\left(\mathrm{MnO}_{2}\right)_{0.6}$ & 26.35 & 25.34 \\
\hline$\left(\mathrm{Y}_{2} \mathrm{O}_{3}\right)_{0.8}\left(\mathrm{Sb}_{2} \mathrm{O}_{3}\right)_{0.2}$ & 8.16 & 8.07 & $\left(\mathrm{Al}_{2} \mathrm{O}_{3}\right)_{0.6}\left(\mathrm{MnO}_{2}\right)_{0.4}$ & 48.72 & 24.58 \\
\hline$\left(\mathrm{Ga}_{2} \mathrm{O}_{3}\right)_{0.2}\left(\mathrm{Bi}_{2} \mathrm{O}_{3}\right)_{0.8}$ & 7.34 & 1.87 & $\left(\mathrm{Y}_{2} \mathrm{O}_{3}\right)_{0.8}(\mathrm{MnO})_{0.2}$ & 8.04 & 7.95 \\
\hline$\left(\mathrm{Ga}_{2} \mathrm{O}_{3}\right)_{0.8}\left(\mathrm{Bi}_{2} \mathrm{O}_{3}\right)_{0.2}$ & 7.32 & 6.88 & $\left(\mathrm{Y}_{2} \mathrm{O}_{3}\right)_{0.2}(\mathrm{MnO})_{0.8}$ & 6.43 & 6.32 \\
\hline$\left(\mathrm{Al}_{2} \mathrm{O}_{3}\right)_{0.2}\left(\mathrm{Bi}_{2} \mathrm{O}_{3}\right)_{0.8}$ & 20.04 & 19.54 & & & \\
\hline
\end{tabular}

$S_{\text {уд }}^{0}$ - удельная поверхность неотожженных образцов; $S_{\text {уд }}^{1}$ - удельная поверхность после десятиминутного отжига при температуре $530{ }^{\circ} \mathrm{C}$

$S_{\mathrm{yд}}^{0}-$ specific surface of unannealed samples; $S_{\mathrm{yд}}^{1}$ - specific surface after ten minutes of annealing at $530{ }^{\circ} \mathrm{C}$ 
$\mathrm{Ga}_{2} \mathrm{O}_{3}+$ хемостимулятор, происходит изменение удельной поверхности ( в 2 раза). При отжиге всех композиций с участием $\mathrm{Y}_{2} \mathrm{O}_{3}$ резкого изменения площади удельной поверхности практически не наблюдается ( 1.1-1.2 раза).

Термогравиметрические исследования в сочетании с данными РФА показали, что в присутствии $\mathrm{Al}_{2} \mathrm{O}_{3}$ изменяются температурный диапазон и характер превращений хемостимуляторов. Индивидуальный $\mathrm{Bi}_{2} \mathrm{O}_{3}$ и этот же оксид, находящийся в композициях с $\mathrm{Ga}_{2} \mathrm{O}_{3}$ и $\mathrm{Y}_{2} \mathrm{O}_{3}$, в интервале температур до $650{ }^{\circ} \mathrm{C}$ не испытывают никаких изменений, а в присутствии $\mathrm{Al}_{2} \mathrm{O}_{3}$ в интервале $460-550{ }^{\circ} \mathrm{C}$ наблюдается эндотермический эффект, что интерпретировано, с учетом данных РФА, как переход в ВiО. Для индивидуального $\mathrm{Sb}_{2} \mathrm{O}_{3}$ и его композиций с $\mathrm{Ga}_{2} \mathrm{O}_{3}$ и $\mathrm{Y}_{2} \mathrm{O}_{3}$ при нагревании на воздухе в интервале 460-550 ${ }^{\circ} \mathrm{C}$ зафиксирован экзотермический эффект, что обусловлено окислением до $\mathrm{Sb}_{2} \mathrm{O}_{4}$ (РФА). $\mathrm{B}$ присутствии $\mathrm{Al}_{2} \mathrm{O}_{3}$ в интервале температур 460$510{ }^{\circ} \mathrm{C}$ отмечен небольшой экзотермический эффект (окисление до $\mathrm{Sb}_{2} \mathrm{O}_{4}$, РФА), с последующим эндотермическим эффектом в интервале температур 510-580 ${ }^{\circ} \mathrm{C}\left(\mathrm{Sb}_{2} \mathrm{O}_{4} \rightarrow \mathrm{Sb}_{2} \mathrm{O}_{3}, \mathrm{PФA}\right) . \mathrm{MnO}_{2}$ при 618-675 ${ }^{\circ} \mathrm{C}$ претерпевает диссоциативный распад до $\mathrm{Mn}_{2} \mathrm{O}_{3}$, а в композиции с $\mathrm{Al}_{2} \mathrm{O}_{3}$ наблюдается двухэтапная потеря массы при более низких температурах (480-567 и 567-618 $\left.{ }^{\circ} \mathrm{C}\right)$, характеризующая частичную более глубокую диссоциацию $\mathrm{MnO}_{2} \rightarrow$ $\mathrm{Mn}_{2} \mathrm{O}_{3} \rightarrow \mathrm{Mn}_{3} \mathrm{O}_{4}$ (РФА). Оксид марганца (II) при 300 $400{ }^{\circ} \mathrm{C}$ превращается в $\mathrm{MnO}_{2}$, который затем при $480-567{ }^{\circ} \mathrm{C}$ переходит в $\mathrm{Mn}_{2} \mathrm{O}_{3}$. Присутствие $\mathrm{Al}_{2} \mathrm{O}_{3}$ в композициях с $\mathrm{MnO}$ приводит к интенсификации превращений $\mathrm{MnO}$ в $\mathrm{Mn}_{3} \mathrm{O}_{4}\left(\mathrm{P} Ф A ; \mathrm{MnO} \rightarrow \mathrm{MnO}_{2} \rightarrow\right.$ $\mathrm{Mn}_{2} \mathrm{O}_{3} \rightarrow \mathrm{Mn}_{3} \mathrm{O}_{4}$ ).

Аддитивность совместного воздействия и отклонения от нее качественно подтверждаются данными элементного анализа полученных оксидных слоев (ЛРСМА). Определение содержания элементов-хемостимуляторов в полученных пленках в сравнении с их содержанием в композициях с инертным компонентом показало, что для композиций с участием $\mathrm{Y}_{2} \mathrm{O}_{3}$ относительное содержание элемента-хемостимулятора в пленках совпадает с его содержанием в исходной композиции во всем интервале составов. При отклонениях же от аддитивности содержание этих элементов больше $\left(\mathrm{Al}_{2} \mathrm{O}_{3}-\mathrm{Sb}_{2} \mathrm{O}_{3}, \mathrm{Al}_{2} \mathrm{O}_{3}-\mathrm{Bi}_{2} \mathrm{O}_{3}\right)$ или $\left(\mathrm{Ga}_{2} \mathrm{O}_{3}-\mathrm{Sb}_{2} \mathrm{O}_{3}\right.$, $\mathrm{Ga}_{2} \mathrm{O}_{3}-\mathrm{Bi}_{2} \mathrm{O}_{3}, \mathrm{Ga}_{2} \mathrm{O}_{3}-\mathrm{MnO}_{2} \mathrm{Ga}_{2} \mathrm{O}_{3}-\mathrm{MnO}_{2}, \mathrm{Al}_{2} \mathrm{O}_{3}-$ $\mathrm{MnO}, \mathrm{Al}_{2} \mathrm{O}_{3}-\mathrm{MnO}_{2}$ ) меньше ожидаемого.

Таким образом, добавки $\mathrm{Ga}_{2} \mathrm{O}_{3}$ к хемостимуляторам интенсифицируют процесс их спекания, что негативно влияет на динамику испарения и существенно снижает хемостимулирующую активность. $\mathrm{B}$ присутствии же $\mathrm{Al}_{2} \mathrm{O}_{3}$ изменяется режим собственных превращений хемостимуляторов $\left(\mathrm{Sb}_{2} \mathrm{O}_{3}\right.$, $\mathrm{Bi}_{2} \mathrm{O}_{3}, \mathrm{MnO}, \mathrm{MnO}_{2}$ ). Эти изменения в поведении оксидов в присутствии инертного оксида алюминия приводят, в конечном счете, к изменению характера их хемостимулирующего воздействия на термооксидирование GaAs.

Для композиций с оксидом иттрия наблюдается аддитивная зависимость от состава композиции не только толщины оксидной пленки на поверхности полупроводника, но и содержания хемостимулирующего компонента в пленке, причем не только для GaAs, но и для InP $[39,40]$, что позволяет проводить тонкое регулирование состава, структуры, а, следовательно, и свойств тонких пленок на поверхности арсенида галлия и фосфида индия.

\section{ПРОЦЕСС ТЕРМООКСИДИРОВАНИЯ InP ПОД ВОЗДЕЙСТВИЕМ ОКСИДНЫХ КОМПОЗИЦИЙ, НАНЕСЕННЫХ НА ЕГО ПОВЕРХНОСТЬ И ВВОДИМЫХ ЧЕРЕЗ ГАЗОВУЮ ФАЗУ}

Нелинейные эффекты, при совместном воздействии хемостимуляторов - это достаточно общее явление, не зависящее ни от природы полупроводниковой подложки (в данном случае арсенид галлия или фосфид индия), ни от способа введения композиции хемостимуляторов в систему: через газовую фазу способом 1 или непосредственно на полупроводник с образованием гетероструктуры ((композиция хемостимуляторов)/полупроводник) способом 2 (по классификации из [11]).

В работах [41-45] исследован процесс термооксидирования гетероструктур $(\mathrm{NiO}+\mathrm{PbO}) / \mathrm{InP}$ и $\left.\left(\mathrm{V}_{2} \mathrm{O}_{5}+\mathrm{PbO}\right) / \mathrm{InP}\right)$. В первом случае композиция хемостимуляторов представляет собой оксиды, действующие на процесс термооксидрования InP по транзитному механизму, во втором же один из оксидов $\left(\mathrm{V}_{2} \mathrm{O}_{5}\right)$ оказывает влияние по каталитическому механизму [46].

На рис. 20 и 21 представлены зависимости толщины $(d)$ и относительной интегральной толщины $\left(d^{R}\right)$ оксидной пленки на поверхности фосфида индия от состава оксидной композиции хемостимуляторов $\mathrm{NiO}+\mathrm{PbO}$ и $\mathrm{V}_{2} \mathrm{O}_{5}+\mathrm{PbO}$.

Анализ зависимостей толщины $(d)$ и относительной интегральной толщины $\left(d^{R}\right)$ от состава оксидной композиции хемостимуляторов позволяет констатировать, что активирующее действие композиций $\mathrm{NiO}+\mathrm{PbO}$ и $\mathrm{V}_{2} \mathrm{O}_{5}+\mathrm{PbO}$ не подчиняется 

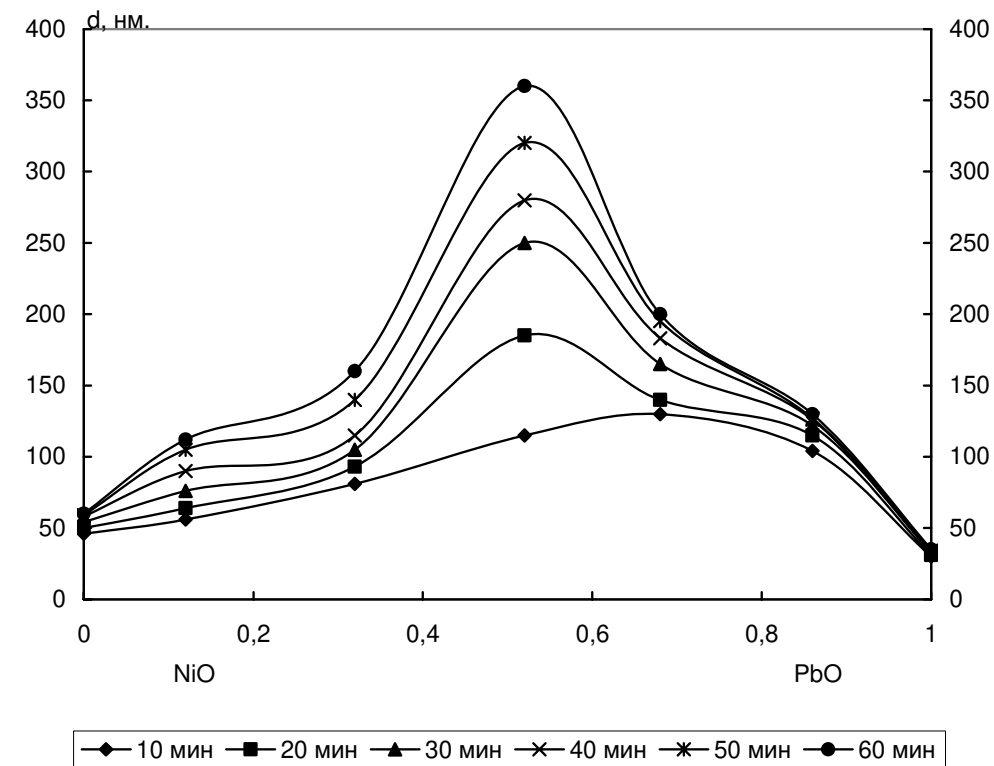

b

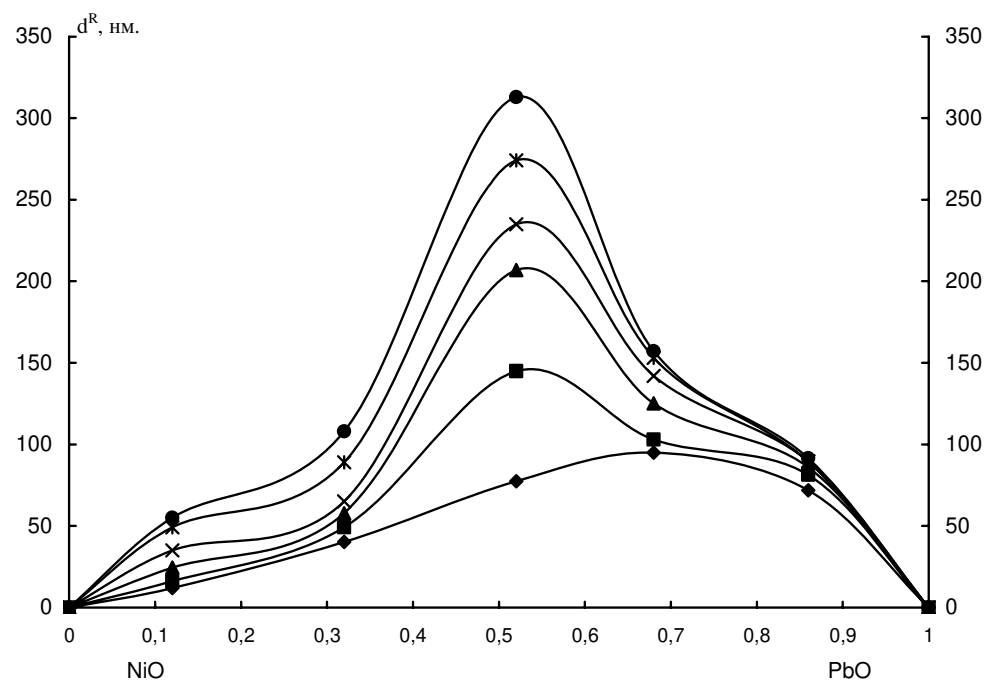

Рис. 20. Зависимость толщины оксидной пленки на поверхности InP от состава композиции оксидов-хемостимуляторов $\mathrm{NiO}$ и $\mathrm{PbO}(a)$ и относительной интегральной толщины оксидной пленки $(b)$

[Fig. 20. Dependence of the thickness of the oxide film on the surface of the InP composition the composition of the oxides-chemostimulators $\mathrm{NiO}$ and $\mathrm{PbO}(a)$ and relative integral thickness of the oxide film $(b)]$

закону аддитивности. В системе наблюдается существенная нелинейность совместного воздействия оксидов, и достигаемая толщина сформированной пленки оказывается всегда больше ожидаемой в предположении независимого параллельного активирующего действия.

Для композиции $\mathrm{NiO}+\mathrm{PbO}$ при общем положительном отклонении от аддитивности воздействие оксидов $\mathrm{NiO}$ и $\mathrm{PbO}$ друг на друга различно. Имеет место ярко выраженный максимум при содержании $\mathrm{PbO}$, равном 52 мол. \%. Он хорошо локализован по составу и монотонно усиливается с ростом времени. Такое его поведение авторы связывают с ростом степени превращения компонентов в процессе взаимодействия между хемостимуляторами.

Для композиции $\mathrm{V}_{2} \mathrm{O}_{5}+\mathrm{PbO}$ также имеет место экстремальная зависимость толщины оксидной пленки на поверхности InP от состава оксидной композиции. Для всех времен термооксидирования наиболее яркий эффект взаимного влияния оксидов зафиксирован при содержании 75 мол. \% $\mathrm{V}_{2} \mathrm{O}_{5}$ и усиливается с ростом времени оксидирова- 

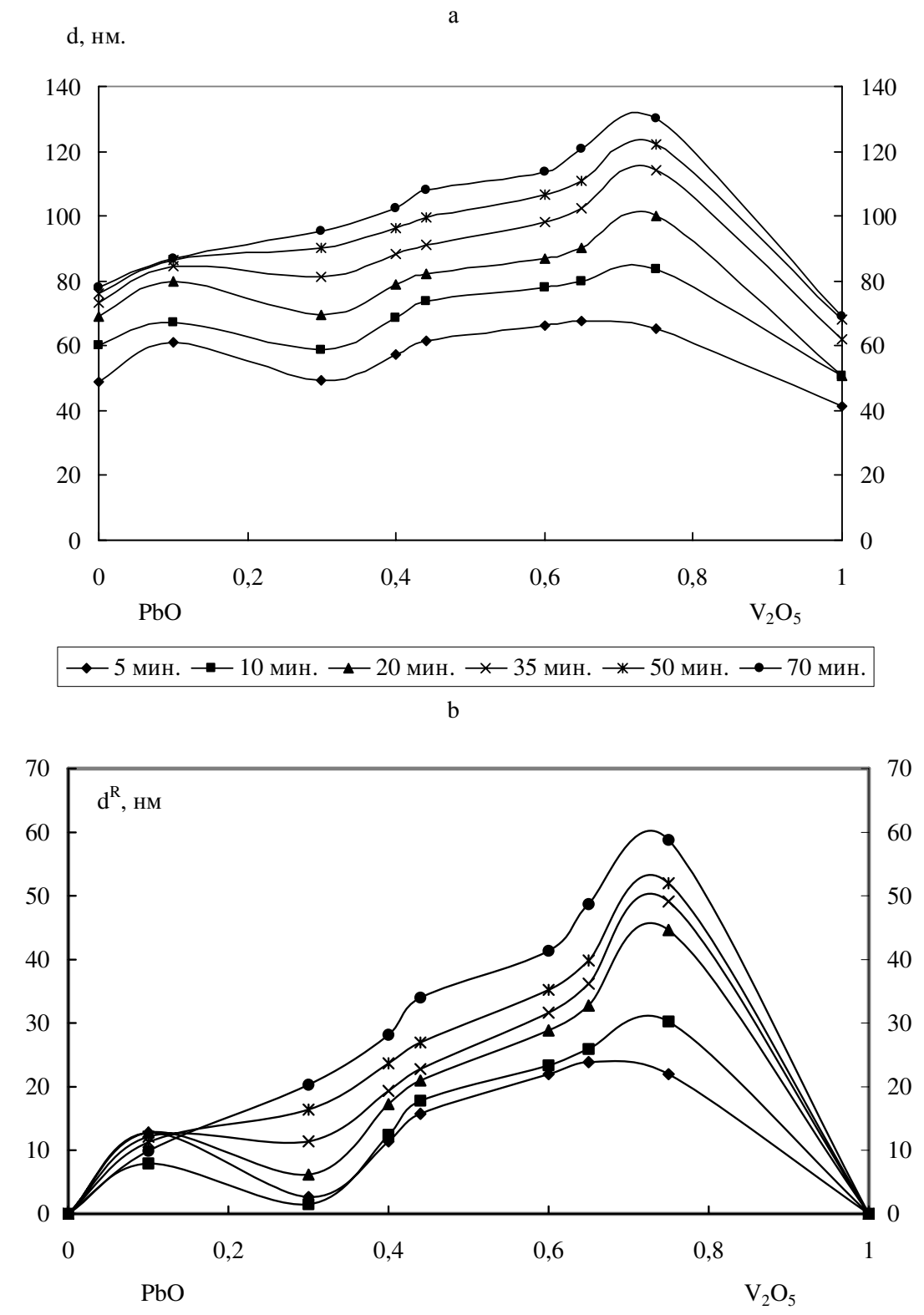

Рис. 21. Зависимость толщины оксидной пленки на поверхности InP от состава композиции оксидов-хемостимуляторов $\mathrm{PbO}$ и $\mathrm{V}_{2} \mathrm{O}_{5}(a)$ и концентрационная зависимость относительной интегральной толщины оксидной пленки $(b)$ [Fig. 21. Dependence of the thickness of the oxide film on the surface of the InP from the composition of oxides-chemostimulators $\mathrm{PbO}$ and $\mathrm{V}_{2} \mathrm{O}_{5}(a)$ and concentration dependence of the relative integral of the thickness of the oxide film $(b)$ ]

ния. Однако с увеличением температуры, при общем положительном характере, отклонение от аддитивной прямой уменьшается, что может быть следствием усиления взаимного влияния оксидов и их связывания.

Исследование термооксидирования гетероструктур $(\mathrm{NiO}+\mathrm{PbO}) / \mathrm{InP}$ и $\left.\left(\mathrm{V}_{2} \mathrm{O}_{5}+\mathrm{PbO}\right) / \mathrm{InP}\right)$ позволило не только подтвердить общность явления неаддитивности совместного действия хемостимуляторов на процесс термооксидирования полупроводников, но и получить на их основе покры- тия с лучшими диэлектрическими свойствами по сравнению с собственным термооксидированием $\mathrm{InP}$, при более щадящем температурном режиме и за меньшее время (наличие положительных отклонений от аддитивности).

Поскольку при оксидировании гетероструктур $\left.\left(\mathrm{V}_{2} \mathrm{O}_{5}+\mathrm{PbO}\right) / \mathrm{InP}\right)$, содержащих оксид-катализатор $\mathrm{V}_{2} \mathrm{O}_{5}$ и оксид-транзитор $\mathrm{PbO}$ (введение хемостимуляторов методом 2 [11]), установлена смена механизмов хемостимулированного оксидирования полупроводника с каталитического на транзитный 
[43], в [47] была рассмотрена возможность реализации аналогичных закономерностей при оксидировании фосфида индия под воздействием композиции оксидов, вводимой через газовую фазу (метод 1 [11]).

При малом времени оксидирования (10 мин) имеет место практически аддитивная зависимость толщины пленки от состава во всем интервале составов композиции оксидов-хемостимуляторов, за исключением состава $20 \% \mathrm{~V}_{2} \mathrm{O}_{5}$, для которого с ростом времени термооксидирования нарастает отрицательное отклонение (рис. 22).

В целом с ростом времени термооксидирования проявляется нелинейный характер зависимости толщины оксидной пленки от состава композиции хемостимуляторов: в интервале составов от $30 \%$ до $80 \% \mathrm{~V}_{2} \mathrm{O}_{5}$ имеет место положительное отклонение от аддитивной прямой, сменяющееся на отрицательное на окончательном этапе оксидирования (40 мин), особенно ярко выраженное для составов с максимальным содержанием оксида ванадия.

При этом даже в случае отрицательного отклонения от аддитивности, наблюдается ускоренное формирование оксидной пленки по сравнению с эталоном (собственное термооксидирование InP в отсутствие хемостимуляторов).

По данным РФА и ЛРСМА было установлено, что пленки в основном состоят из $\mathrm{In}_{2} \mathrm{O}_{3}$, а также включают в себя различные оксиды ванадия и марганца. При добавлении к более эффективному хемостимулятору $\mathrm{V}_{2} \mathrm{O}_{5}$ менее эффективного $\mathrm{MnO}_{2}$ толщина оксидной пленки на InP уменьшается (рис. 22), однако происходит это с отклонением от аддитивности. Общий характер отклонения от аддитивности - отрицательный. При этом имеет место достаточно четко выраженная зависимость отклонения от аддитивности от состава композиции и времени термооксидирования. При минимальном времени термооксидирования, на неразвитой стадии процесса, отклонение от аддитивности минимально. С увеличением времени термооксидирования отрицательное отклонение от аддитивности для большинства составов становится выражено более явно.

Наблюдаемые отклонения от аддитивности можно трактовать как результат взаимного влияния друг на друга хемостимуляторов в исходной композиции, меняющего характер их термопревращений. Индивидуальный оксид $\mathrm{V}_{2} \mathrm{O}_{5}$ претерпевает превращение по схеме $\mathrm{V}_{2} \mathrm{O}_{5} \rightarrow \mathrm{VO}_{2} \rightarrow \mathrm{V}_{2} \mathrm{O}_{3}$. Для оксида марганца обнаружены $\mathrm{MnO}_{2}$ и $\mathrm{Mn}_{2} \mathrm{O}_{3}$, то есть происходит переход $\mathrm{MnO}_{2} \rightarrow \mathrm{Mn}_{2} \mathrm{O}_{3}$, что и приводит, наряду с включением хемостимуляторов в оксидную пленку на поверхности InP, к наблюдаемым нелинейным эффектам зависимости толщины оксидной пленки от состава композиции $\mathrm{V}_{2} \mathrm{O}_{5}+\mathrm{MnO}_{2}$.

Полученные в [47] результаты подтверждают данные, приведенные выше для термооксидирования GaAs, о нелинейности совместного воздействия хемостимуляторов (при наличии взаимодействий между ними) на термооксидирование полупроводников.

В [48] было установлено, что термооксидирование гетероструктуры $\mathrm{V}_{2} \mathrm{O}_{5} / \mathrm{InP}$ протекает по синхронному каталитическому механизму и процесс

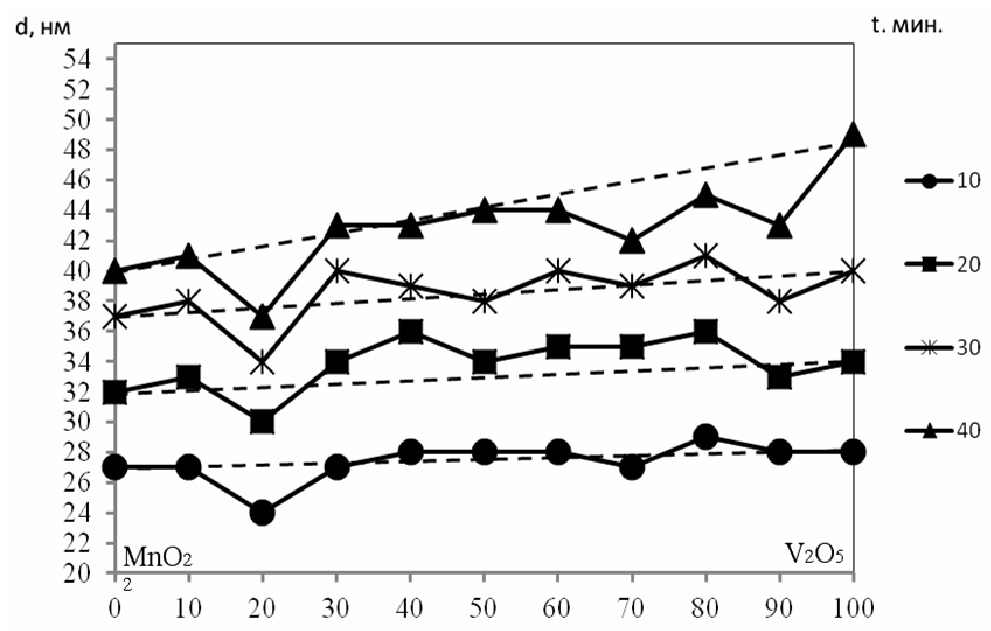

Pис. 22. Зависимость толщины $d$ оксидной пленки, выращенной на $\operatorname{InP}$ при $530{ }^{\circ} \mathrm{C}$ за $10-40$ мин, от состава композиции $\mathrm{V}_{2} \mathrm{O}_{5}+\mathrm{MnO}_{2}$, вводимой через газовую фазу

[Fig. 22. Dependence of the thickness $d$ of the oxide film on InP at $530{ }^{\circ} \mathrm{C}$ for $10-40 \mathrm{~min}$, on the composition of $\mathrm{V}_{2} \mathrm{O}_{5}+\mathrm{MnO}_{2}$ introduced through the gas phase] 
характеризуется значительным (на порядок) снижением эффективной энергии активации (ЭЭА) по сравнению с собственным оксидированием InP: с $\sim 270$ кДж/моль до 230 кДж/моль. При термооксидировании же гетероструктур (90\% $\mathrm{V}_{2} \mathrm{O}_{5}+10 \%$ $\left.\mathrm{MnO}_{2}\right) / \mathrm{InP}$ с добавлением всего $10 \%$ оксида марганца к пентаоксиду ванадия имеет место радикальное изменение кинетики процесса - величина показателя $n$ степенного уравнения [48] значительно меньше 0.5 , что свидетельствует о том, что определяющим процессом является твердофазная реакция, лимитируемая диффузией в твердой фазе. Значение ЭЭА, рассчитанное на основании аррениусовской зависимости усредненной константы скорости, также типично для реакции твердое-твердое без каталитического эффекта.

Основная роль оксида марганца как хемостимулятора, действующего по транзитному механизму, заключается в удержании в растущей пленке фосфора с последующим образованием фосфата индия. Этот факт благоприятно сказывается как на морфологии поверхности пленки, так и на ее электрофизических свойствах.

На основании всех изложенных выше результатов можно утверждать, что присутствие в системе композиций хемостимуляторов оказывает решающее влияние на процесс термооксидирования InP и $\mathrm{GaAs}$, независимо от способа их введения в нее (способ 1 и способ 2 [43]). Композиции хемостимуляторов, радикально влияя на механизм оксидирования InP и GaAs, состав и структуру образующихся на их поверхности пленок, позволяют оказывать целенаправленное воздействие и на их свойства (одно из которых рассмотрено в следующем пункте).

\section{ГАЗОЧУВСТВИТЕЛЬНЫЕ СВОЙСТВА ТОНКИХ ПЛЕНОК НА ПОВЕРХНОСТИ GaAs, ПОЛУЧЕННЫХ ПОД ВОЗДЕЙСТВИЕМ КОМПОЗИЦИЙ ХЕОСТИМУЛЯТОРОВ, ВВОДИМЫХ ЧЕРЕЗ ГАЗОВУЮ ФАЗУ}

В предыдущем разделе уже говорилось о положительном действии композиций оксидов-хемостимуляторов на функциональные свойства пленок, получаемых на поверхности полупроводников. В работах $[49,50]$ рассмотрена возможность использования выращенных под воздействием композиций хемостимуляторов тонких пленок в качестве твердотельного элемента газовых сенсоров. Исследуемыми газами являлись аммиак и угарный газ (рис. 23, 24).
Для обоих исследованных случаев полученные пленки обладают удовлетворительными газочувствительными свойствами, и имеет место экстремальная зависимость газовой чувствительности от температуры. Но при этом для пленок, синтезированных под воздействием композиций $\mathrm{V}_{2} \mathrm{O}_{5}$ $+\mathrm{Sb}_{2} \mathrm{O}_{3}$, максимальная газовая чувствительность достигается при более низкой температуре (200 ${ }^{\circ} \mathrm{C}$ вместо $230-250{ }^{\circ} \mathrm{C}$ ), что, с одной стороны, снижает энергопотребление потенциального газового сенсора, а с другой - позволяет адсорбированным на поверхности пленки молекулам активно вступать в химические реакции. При этом сама ее величина несколько возрастает от 1.20 до 1.31 (для аммиака).

Общей тенденцией полученных результатов является более высокая чувствительность всех пленок к аммиаку по сравнению с угарным газом.

Для пленок, выращенных под воздействием композиций $\mathrm{PbO}+\mathrm{Bi}_{2} \mathrm{O}_{3}$, были установлены температурные зависимости концентрации и подвижности свободных носителей заряда в оксидных пленках на поверхности GaAs.

Эти результаты показывают, что проводимость пленок, сформированных термооксидированием $\mathrm{GaAs}$, определяется увеличением концентрации носителей заряда с ростом температуры, тогда как подвижность меняется незначительно.

Исходя из этого, можно сделать определенные выводы о механизме газовой чувствительности выращенных на поверхности GaAs тонких пленок. Вакансии кислорода в растущих оксид-

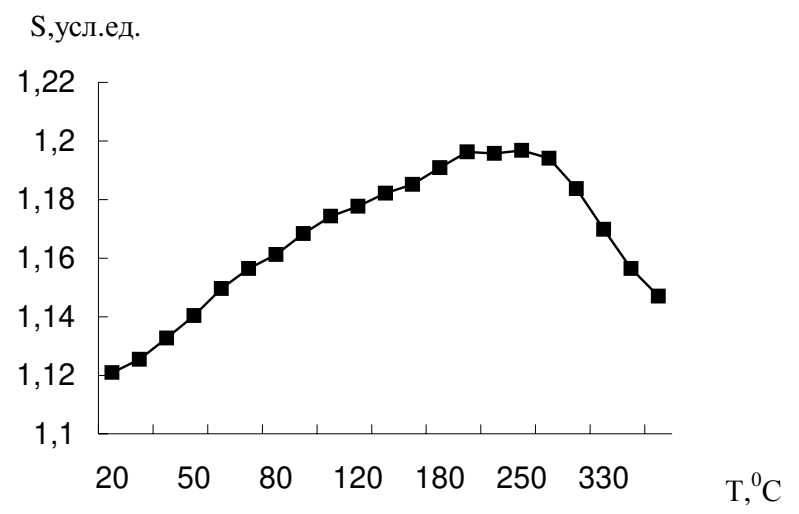

Рис. 23. Зависимость газовой чувствительности от температуры тонких пленок, полученных под воздействием композиции $50 \% \mathrm{PbO}+50 \% \mathrm{Bi}_{2} \mathrm{O}_{3}$ в парах аммиака

[Fig. 23. Dependence of gas sensitivity on the temperature of thin films obtained under the influence of $50 \%$ $\mathrm{PbO}+50 \% \mathrm{Bi}_{2} \mathrm{O}_{3}$ composition in ammonia vapors] 
a

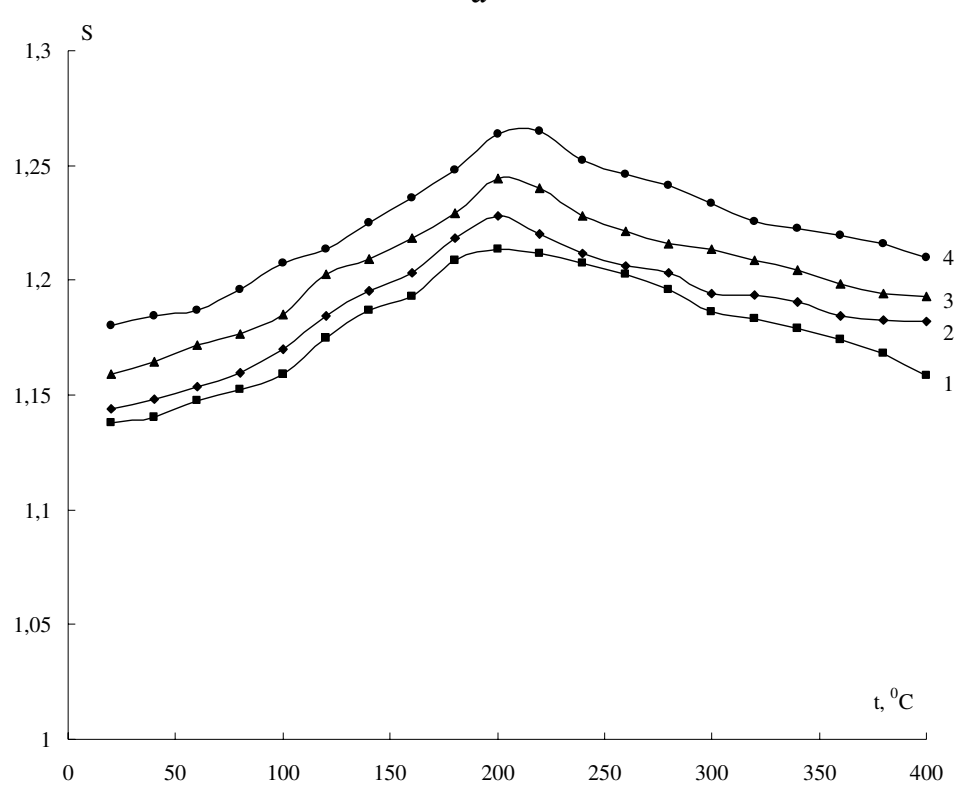

b

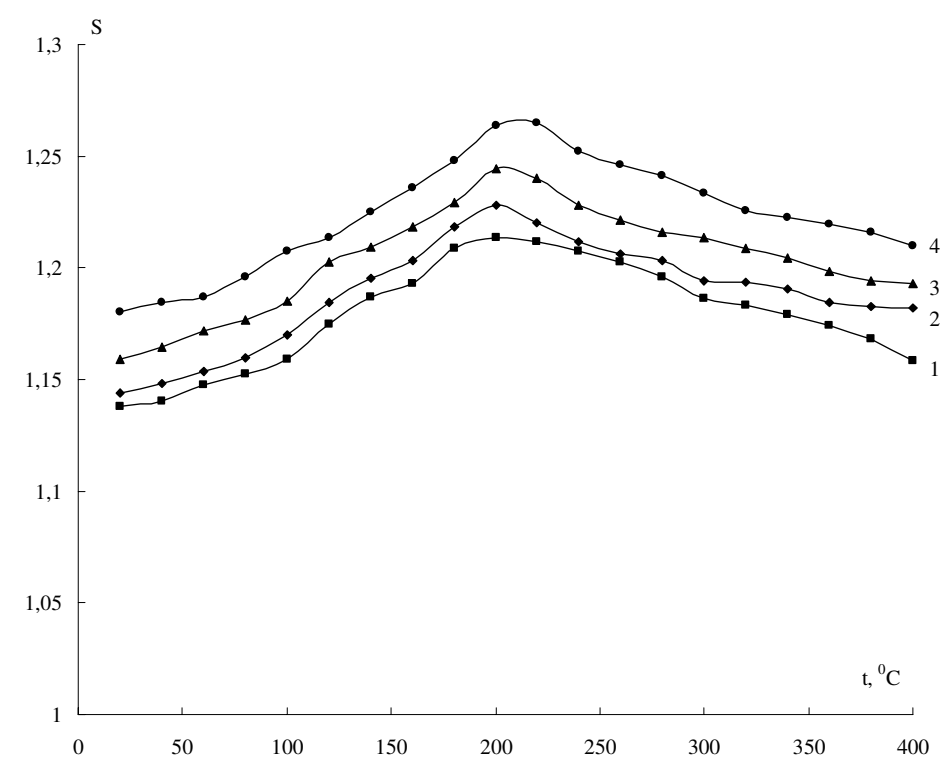

Рис. 24. Температурная зависимость газовой чувствительности пленок на поверхности GaAs, полученных под воздействием композиций $\mathrm{V}_{2} \mathrm{O}_{5}+\mathrm{Sb}_{2} \mathrm{O}_{3}$ разного состава, в присутствии $\mathrm{CO}(a)$ и $\mathrm{NH}_{3}(b): 1-80 \% \mathrm{~V}_{2} \mathrm{O}_{5}+$ $20 \% \mathrm{Sb}_{2} \mathrm{O}_{3} ; 2-60 \% \mathrm{~V}_{2} \mathrm{O}_{5}+40 \% \mathrm{Sb}_{2} \mathrm{O}_{3} ; 3-40 \% \mathrm{~V}_{2} \mathrm{O}_{5}+60 \% \mathrm{Sb}_{2} \mathrm{O}_{3} ; 4-20 \% \mathrm{~V}_{2} \mathrm{O}_{5}+80 \% \mathrm{Sb}_{2} \mathrm{O}_{3}$

[Fig. 24. Temperature dependences of gas sensitivity for the films on the surface GaAs caused by the influence of the compositions of $\mathrm{V}_{2} \mathrm{O}_{5}+\mathrm{Sb}_{2} \mathrm{O}_{3}$ different composition, in the presence of $\mathrm{CO}(a)$ and $\mathrm{NH}_{3}(b): 1-80 \% \mathrm{~V}_{2} \mathrm{O}_{5}+$ $\left.20 \% \mathrm{Sb}_{2} \mathrm{O}_{3} ; 2-60 \% \mathrm{~V}_{2} \mathrm{O}_{5}+40 \% \mathrm{Sb}_{2} \mathrm{O}_{3} ; 3-40 \% \mathrm{~V}_{2} \mathrm{O}_{5}+60 \% \mathrm{Sb}_{2} \mathrm{O}_{3} ; 4-20 \% \mathrm{~V}_{2} \mathrm{O}_{5}+80 \% \mathrm{Sb}_{2} \mathrm{O}_{3}\right]$

ных пленках служат центрами для хемосорбции атмосферного кислорода, что обеспечивает установленный в работе $n$-тип их проводимости. При помещении пленок в атмосферу аммиака определяемый газ вытесняет химически связанный кислород и при этом окисляется. В ходе этой реакции высвобождаются электроны, что приводит к увели- чению электропроводности оксидной пленки или к уменьшению сопротивления, пропорционально количеству газа.

Важным фактором, влияющим на газочувствительные свойства пленки, является степень ее легирования используемым хемостимулятором. В связи с этим представляется интересным исследование 
газочувствительных свойств пленок, полученных под воздействием композиций, в которых один из компонентов является инертным (особенно хорошие результаты были, как показано выше, достигнуты для композиций с участием оксида иттрия). Использование инертного компонента позволяет управлять составом тонкой пленки, растущей на поверхности полупроводника, а, следовательно, и величиной газового отклика таких пленок.

\section{ЗАКЛЮЧЕНИЕ}

Закономерности, полученные при исследовании процессов термического оксидирования GaAs и InP под воздействием бинарных оксидных композиций, можно обобщить следующим образом: если оба оксида композиции обладают хемостимулирующим действием, то, независимо от способа введения композиции в окислительную среду и от выбора полупроводниковой подложки, будут наблюдаться различные по характеру нелинейные эффекты зависимости толщины оксидной пленки на поверхности полупроводника от состава композиции хемостимуляторов. Взаимное влияние хемостимуляторов, приводящее к отклонениям от аддитивной зависимости при введении их через газовую фазу, локализовано в твердой и газовой фазах, а на поверхности полупроводника пренебрежимо мало. В случае использования композиций с участием инертного компонента становится возможным получить аддитивную зависимость толщины оксидной пленки на поверхности полупроводника от состава композиции оксид-хемостимулятор + инертный компонент во всем интервале составов композиции. Использование композиций хемостимулят ор+хемостимулятор и хемостимулятор+инертный компонент позволяет целенаправленно модифицировать свойства оксидных пленок на поверхности GaAs и InP с целью повышения их функциональности (электрофизические свойства, морфология поверхности, газочувствительные свойства).

Результаты исследований получены на оборудовании Центра коллективного пользования Воронежского государственного университета. URL: http://ckp.vsu.ru

Работа выполнена при поддержке гранта РФФИ № №18-03-00354_a

\title{
NONLINEAR EFFECTS OF OXIDES OF $p$ - AND $d$-ELEMENTS' COACTIONS IN FORMATION OF THIN FILMS ON THE GaAs AND InP SURFACES OVERVIEW
}

\author{
(C) 2018 V. F. Kostryukov, I. Ya. Mittova, E. V. Tomina, B. V. Sladkopevtsev, A. S. Parshina, \\ D. S. Balasheva \\ (CVoronezh State University, 1, Universitetskaya pl., 394018 Voronezh, Russia \\ e-mail:vc@chem.vsu.ru
}

Received 03.09.2018

\begin{abstract}
The thermal oxidation process of gallium arsenide and indium phosphide under the influence of binary oxides compositions has been studied (chemostimulator+chemostimulator and chemostimulator+inert component). Oxides-chemostimulators were oxides of $p$ - and $d$-elements' $\left(\mathrm{Sb}_{2} \mathrm{O}_{3}, \mathrm{Bi}_{2} \mathrm{O}_{3}, \mathrm{PbO}, \mathrm{CrO}_{3}, \mathrm{~V}_{2} \mathrm{O}_{5}, \mathrm{MnO}_{2}, \mathrm{MnO}\right)$, inerts components were $-\mathrm{Ga}_{2} \mathrm{O}_{3}, \mathrm{Al}_{2} \mathrm{O}_{3}$ и $\mathrm{Y}_{2} \mathrm{O}_{3}$. Тhe nonlinear effects of the oxide film thickness on the GaAs and InP surfaces from the compositions oxides-chemostimulators have been studied and interpreted. Nonlinear effects are characterized by different signs of deviation from the additive straight - negative, positive and alternating. There is a clear correlation between the existence of acid-base and oxidation-reduction interactions in the compositions chemostimulators and nonlinear effect's sign. If there is acid-base and oxidation-reduction interactions between the compositions of the oxides, then a positive nonlinear effect will be observed, increasing with growing time and temperature of oxidation. With the weakening of acid-base and oxidation-reduction interactions, a positive deviation from additive function is replaced by alternating signs. In case of the complete absence of interaction between the oxides in the composition, there is a negative deviation from additive function, increasing with growing time and temperature of oxidation. The possibility of obtaining the additive function for the entire range of compositions action of
\end{abstract}


the oxide film thickness on the GaAs surfaces from the compositions oxide-chemostimulator+inert component has been proven (inert component $-\mathrm{Y}_{2} \mathrm{O}_{3}$ ). The study of GaAs thermal oxidation under the influence of $\mathrm{Sb}_{2} \mathrm{O}_{3}+\mathrm{Ga}_{2} \mathrm{O}_{3}$ compositions showed a significant negative departure of the oxide film thickness from the additive line for low $\mathrm{Ga}_{2} \mathrm{O}_{3}$ concentrations. When the $\mathrm{Ga}_{2} \mathrm{O}_{3}$ concentration in the compositions was higher than $40 \mathrm{~mol} \%$, the oxide film thickness grown on GaAs was an additive function of the activator composition. The nonlinear effects observed were caused by the influence of small $\mathrm{Ga}_{2} \mathrm{O}_{3}$ additions on the vaporization dynamics of antimony oxide through the enhancement of $\mathrm{Sb}_{2} \mathrm{O}_{3}$ sintering during the experiment. The spation localization of binding interactions between oxideschemostimulators was revealed, which leads to the nonlinear effects. The solid-phase interactions enhance the chemostimulating activities of both oxides (a positive nonlinear effect takes place). The gas-phase interactions cause a marked negative deviation from the additive chemical stimulation effect The solid-phase interactions between the chemostimulators (during the evaporation of their mixtures) somewhat extend the lifetime of molecular oxide species in the vapor, giving rise to a positive thermal oxidation effect. The gas-phase interactions between the (chemostimulators are mainly dissociative. They reduce the chemostimulating effect and make a negative contribution to the nonlinear effects. The thin films of the GaAs and InP surfaces synthesized using this method have better electrophysical properties and exhibit a gas-sensitive response in a reducing gases atmosphere.

Keywords: gallium arsenide, indium phosphide, thermal oxidation, chemostimulators, nanoscale films, nonlinear effects, heterostructures, gas sensitivity.

DOI: https://doi.org/10.17308/kcmf.2018.20/625

\section{ACKNOWLEDGMENTS}

The research results were obtained using the equipment of the Center for Collective Use of Equipment Voronezh State University. URL: http:// ckp.vsu.ru

The reported study was supported by a grant from the Russian Foundation for Basic Research (project No. №18-03-00354_a).

\section{REFERENCES}

1. Mittova I. Ya., Vasil'eva V. V., Terehov V. A. Izvestija AN SSSR. Serija Neorganicheskie materialy [News of the Academy of Sciences of the USSR. Series Inorganic Materials], 1988, vol. 24, no. 12, pp. 1941-1944. (in Russ.)

2. Mittova I. Ya., Sviridova V. V., Semenov V. N., Terekhov V. A. Izvestija AN SSSR. Serija Neorganicheskie materialy [News of the Academy of Sciences of the USSR. Series Inorganic Materials], 1989, vol. 25, no. 6, pp. 908911. (in Russ.)

3. Mittova I. Ya., Sviridova V. V., Fetisova S. V. Izvestija AN SSSR. Serija Neorganicheskie Materialy [News of the Academy of Sciences of the USSR. Series Inorganic Materials], 1992, vol. 28, no. 9, pp. 1829-1832. (in Russ.)

4. Mittova I. Ya., Sviridova V. V., Fetisova S. V. Izvestija AN SSSR. Serija Neorganicheskie Materialy [News of the Academy of Sciences of the USSR. Series Inorganic Materials], 1990, vol. 26, no. 10, pp. 2013-2016. (in Russ.)

5. Mittova I. Ya., Sviridova V. V., Fetisova S. V. Izvestija AN SSSR. Serija Neorganicheskie Materialy [News of the Academy of Sciences of the USSR. Series Inorganic
Materials], 1991, vol. 27, no. 12, pp. 2488-2490. (in Russ.)

6. Mittova I. Ya., Pshestanchik V. R., Malyshev O. M. Izvestija AN SSSR. Serija Neorganicheskie Materialy [News of the Academy of Sciences of the USSR. Series Inorganic Materials], 1992, vol. 28, no. 5, pp. 2041-2044. (in Russ.)

7. Mittova I. Ya., Sviridova V. V., Koljukaeva I. A. Izvestija AN SSSR. Serija Neorganicheskie Materialy [News of the Academy of Sciences of the USSR. Series Inorganic Materials], 1989, vol. 25, no. 12, pp. 1954-1958. (in Russ.)

8. Mittova I. Ya., Pshestanchik V. R., Soshnikov V. V. Doklady chemistry [Reports of the Russian Academy of Sciences], 1997, vol. 354, no. 3, pp. 343-345. (in Russ.)

9. Mittova I. Ya., Soshnikov V. V., Kashkarov V. M., Pshestanchik V. R. Neorganicheskie Materialy [Inorganic Materials], 1999, vol. 35, no. 1, pp. 13-16. (in Russ.)

10. Mittova I. Ya. Vestnik VGU. Serija: Himija, biologija [Bulletin of the VSU. Series: Chemistry, Biology], 2000, no. 2, pp. 5-12. (in Russ.)

11. Mittova I. Ya. Inorganic Materials, 2014, vol. 50, no. 9, pp. 874-881. DOI: https://doi.org/10.1134/ S0020168514090088

12. Mittova I. Ya., Pshestanchik V. R., Kostryukov V. F. Doklady chemistry [Reports of the Russian Academy of Sciences], 1996, vol. 349, no. 5, pp. 641-643. (in Russ.)

13. Mittova I. Ya., Pshestanchik V. R., Kostryukov V. F., Konstantinov A. E. Poverhnost' [Journal of Surface Investigation: X-Ray, Synchrotron and Neutron Techniques], 1996, no. 8, pp. 17-22. (in Russ.)

14. Mittova I. Ya., Pshestanchik V. R., Kostryukov V. F. Russian Jjournal of Inorganic Chemistry, 1997, vol. 42, no. 2, pp. 182-186. (in Russ.) 
15. Mittova I. Ya., Kostryukov V. F., Pshestanchik V. R., Kashkarov V. M., Prokin A. N. Russian Journal of Inorganic Chemistry, 2001, vol. 46, no. 5, pp. 723-727.

16. Mittova I. Ya., Pshestanchik V. R., Kostryukov V. F. Doklady Chemistry, 2001, vol. 378, no. 4-6, pp. 165-167. DOI: https://doi.org/10.1023/a:1019238812687

17. Mittova I. Ya., Pshestanchik V. R., Kostryukov V. F. Journal of Surface Investigation: X-Ray, Synchrotron and Neutron Techniques, 1998, no. 4, pp. 499-506.

18. Mittova I. Ya., Pshestanchik V. R., Kostryukov V. F. Nelinejnye ehffekty $v$ processah aktivirovannogo okisleniya GaAs [Nonlinear effects in the activated oxidation of GaAs]. Voronezh, Izdatelsko-poligraficheskij centr Voronezhskogo gosudarstvennogo universiteta, 2008, 160 p. (in Russ.)

19. Mittova I. Ya., Pshestanchik V. R., Pinyaeva O. A., Kostryukov V. F., Skorokhodova S. M. Doklady Chemistry, 2002, vol. 385, no. 4-6, pp. 212-214. DOI: https://doi. org/10.1023/a:1019998719921

20. Mittova I. Ya., Pshestanchik V. R., Pinyaeva O. A., Pukhova V. V., Skorokhodova S. M. Russian Journal of Inorganic Chemistry, 2003, vol. 48, no. 7, pp. 977-981.

21. Mittova I. Ya., Pukhova V. V., Pinyaeva O. A., Emelyanova A. A. Russian Microelectronics, 2001, vol. 30, no. 2, pp. 127-131. DOI: https://doi.org/10.1023/ A: 1009433927773

22. Mittova I. Ya., Pshestanchik V. R., Kostryukov V. F., Donkareva I. A., Saratova A. Yu. Russian Journal of Inorganic Chemistry, 2004, vol. 49, no. 7, pp. 991-994.

23. Mittova I. Ya., Kostryukov V. F., Donkareva I. A., Pshestanchik V. R., Lopatin S. I., Saratova A. Yu. Russian Journal of Inorganic Chemistry, 2005, vol. 50, no. 6, pp. 869-873.

24. Mittova I. Ya., Kostryukov V. F. Nanosystems: Physics, Chemistry, Mathematics, 2015, vol. 6, no. 3, pp. 424434. DOI: https://doi.org/10.17586/2220-8054-2015-6-3424-434 Available at: http://nanojournal.ifmo.ru/en/articles2/volume6/6-3/chemistry/paper12/

25. Mittova I. Ya., Pshestanchik V. R., Kostryukov V. F., Donkareva I. A. Doklady chemistry, 2002, vol. 386, no. 46, pp. 258-260. DOI: https://doi.org/10.1023/ A: 1020731005579

26. Mittova I. Ya., Pshestanchik V. R., Kostryukov V. F., Donkareva I. A. Russian Jjournal of Inorganic Chemistry, 2003, vol. 48, no. 4, pp. 480-482.

27. Kostryukov V. F., Pshestanchik V. R., Donkareva I. A., Agapov B. L., Mittova I. Ya., Lopatin S. I. Russian Journal of Inorganic Chemistry, 2007, vol. 52, no. 10, pp. 1498-1502. DOI: https://doi.org/10.1134/ S0036023607100038

28. Kostryukov V. F. Condensed Matter and Interphase, 2008, vol. 10, no. 2, pp. 122-131. Available at: http://www. kcmf.vsu.ru/resources/t_10_2_2008_005.pdf (in Russ.)

29. Mittova I. Ya., Kostryukov V. F., Pshestanchik V. R., Donkareva I. A., Agapov B. L. Russian Journal of Iinorganic Chemistry, 2008, vol. 53, no. 7, pp. 1018-1023. DOI: https://doi.org/10.1134/S0036023608070085
30. Kostryukov V. F., Donkareva I. A., Pshestanchik V. R., Agapov B. L., Mittova I. Ya., Lopatin S. I. Russian Journal of Inorganic Chemistry, 2008, vol. 53, no. 8, pp. 1273-1277. DOI: https://doi.org/10.1134/ S0036023608080056

31. Kazenas E. K. Termodinamika isparenija oksidov [Thermodynamics of Evaporation of Oxides], Moscow, LKI Publ., 2007, 474 p. (in Russ.)

32. Mittova I. Ya., Lopatin S. I., Pshestanchik V. R., Kostryukov V. F., Sergeeva A. V., Penskoi P. K. Russian Journal of Inorganic Chemistry, 2005, vol. 50, no. 10, pp. 1488-1491.

33. Penskoi P. K., Kostryukov V. F., Pshestanchik V. R., Mittova I. Ya., Kutsev S. V., Kuznetsova I. V. Russian Journal of Inorganic Chemistry, 2009, vol. 54, no. 10, pp. 15641570. DOI: https://doi.org/10.1134/S0036023609100118

34. Kozhevnikova T. V., Penskoi P. K., Kostryukov V. F., Mittova I. Y., Kuznetsova I. V., Kutsev S. V. Russian Journal of Inorganic Chemistry, 2010, vol. 55, no. 12, pp. 18571862. DOI: https://doi.org/10.1134/S0036023610120077

35. Penskoi P. K., Kostryukov V. F., Pshestanchik V. R., Mittova I. Ya. Doklady Chemistry, 2007, vol. 414, no. 2, pp. 152-154. DOI: https://doi.org/10.1134/ S0012500807060055

36. Penskoi P. K., Pshestanchik V. R., Kostryukov V. F., Agapov B. L., Mittova I. Ya., Kuznetsova I. V. Russian Journal of Inorganic Chemistry, 2008, vol. 53, no. 2, pp. 186-191. DOI: https://doi.org/10.1007/s11502-008-2006-0

37. Penskoi P. K., Mittova I. Ya., Kostryukov V. F., Kononova E. Yu., Reutova E. A. Condensed Matter and Interphase, 2008, vol. 10, no. 3, pp. 236-243. Available at: http://www.kcmf.vsu.ru/resources/t_10_3_2008_005.pdf (in Russ.)

38. Kozhevnikova T. V., Penskoi P. K., Kostryukov V. F., Mittova I. Ya., Agapov B. L., Kuznetsova I. V., Kutsev S. V. Condensed Matter and Interphase, 2010, vol. 12, no. 3, pp. 212-225. Available at: http://www.kcmf.vsu.ru/resources/t_12_3_2010_003.pdf (in Russ.).

39. Kostryukov V. F., Mittova I. Ya. Patent RF, no. 2538415,2015 . (in Russ.)

40. Kostryukov V. F., Mittova I. Ya. Patent RF, no. 2632261, 2017. (in Russ.)

41. Mittova I. Ya., Tomina E. V., Samsonov A. A., Lukin A. N., Simonov S. P. Inorganic Materials, 2005, vol. 41, no. 4, pp. 323-330. DOI: https://doi.org/10.1007/ s10789-005-0132-y

42. Mittova I. Ya., Samsonov A. A. Inorganic Materials, 2006, vol. 42, no. 8, pp. 819-825. DOI: https://doi. org/10.1134/S0020168506080024

43. Ievlev V. M., Mittova I. Ya., Samsonov A. A., Tomina E. V., Kashkarov V. M. Doklady Chemistry, 2007, vol. 417, no. 2, pp. 277-281. DOI: https://doi.org/10.1134/ S0012500807120014

44. Samsonov A. A., Mittova I. Y., Tomina E. V., Lukin A. N., Valyukhov D. P. Inorganic Materials, 2011, vol. 47, no. 2, pp. 100-106. DOI: https://doi.org/10.1134/ S0020168511020154 
45. Mittova I. Ya., Shvets V. A., Tomina E. V., Samsonov A. A., Sladkopevtsev B. V., Tret'yakov N. N. Inorganic Materials, 2013, vol. 49, no. 10, pp. 963-970. DOI: https://doi.org/10.1134/S0020168513100075

46. Mittova I. Ya., Tomina E. V., Lapenko A. A., Sladkopevtsev B. V. Nanosystems: Physics, Chemistry, Mathematics, 2012, vol. 3, no. 2, pp. 116-138. (in Russ.)

47. Tretiakov N. N., Mittova I. Ya., Kozik V. V., Sladkopevtcev B. V., Kostryukov V. F., Studenikina Y. I. Russian Physics Journal, 2014, vol. 57, no. 7/2, pp. 186-191. (in Russ.)

48. Mittova I. Ya., Tret'yakov N. N., Kostryukov V. F., Sladkopevtsev B. V. Russian Journal of General Chemistry,
2015, vol. 85, no. 4, pp. 796-801. DOI: https://doi. org $/ 10.1134 / \mathrm{S} 1070363215040040$

49. Tret'yakov N. N., Shchedrina V. E., Sladkopevtsev B. V., Samsonov A. A., Mittova I. Ya. Condensed Matter and Interphase, 2016, vol. 18, no. 2, pp. 256-264. Available at: https://journals.vsu.ru/kcmf/article/view/132/119 (in Russ.)

50. Kostryukov V. F., Mittova I. Ya. Inorganic Materials, 2015, vol. 51, no. 5, pp. 479-483. DOI: https://doi. org/10.1134/S0020168515040056

51. Kostryukov V. F., Mittova I. Ya., Dimitrenko A. A. Inorganic Materials, 2017, vol. 53, no. 5, pp. 451-456. DOI: https://doi.org/10.1134/S0020168517050132
Кострюков Виктор Федорович-д. х. н., доцент, доцент кафедры материаловедения и индустрии наносистем, Воронежский государственный университет, Воронеж, Россия; тел.: +7 (473) 2208356; e-mail: vc@ chem.vsu.ru

Миттова Ирина Яковлевна - д. х. н., професcop, профессор кафедры материаловедения и индустрии наносистем, Воронежский государственный университет, Воронеж, Россия; тел.: +7 (473) 2208356, e-mail: imittova@mail.ru

Томина Елена Викторовна - д. х. н., доцент, доцент кафедры материаловедения и индустрии наносистем, Воронежский государственный университет, Воронеж, Россия; тел.: +7(473) 2208356; e-mail: tomina-e-v@yandex.ru

Сладкопевцев Борис Владимирович - к. х. н., доцент кафедры материаловедения и индустрии наносистем, Воронежский государственный университет, Воронеж, Россия; тел.: +7(473) 2208356; e-mail:dp-kmins@yandex.ru

Паршина Анна Сергеевна - студент кафедры материаловедения и индустрии наносистем, Воронежский государственный университет, Воронеж, Россия; тел.: +7(473) 2208356; e-mail: anyuta_ parshina@mail.ru

Балашева Дарья Степановна - студент кафедры материаловедения и индустрии наносистем, Воронежский государственный университет, Воронеж, Россия; тел.: +7 (473) 2208356; e-mail: balasheva.98@mail.ru
Victor F. Kostryukov - Dr. Sci. (Chem.), Associate Professor, Associate Professor of the Department of Materials Science and Industry of Nanosystems, Voronezh State University, Voronezh, Russia; tel.: +7 (473) 2208356, e-mail: vc@chem.vsu.ru

Irina Y. Mittova - Dr. Sci. (Chem.), Full Professor, Professor of the Department of Materials Science and Industry of Nanosystems, Voronezh State University, Voronezh, Russia; tel.: +7 (473) 2208356, e-mail: imittova@mail.ru

Elena V. Tomina - Dr. Sci. (Chem.), Associate Professor, Associate Professor of the Department of Materials Science and Industry of Nanosystems, Voronezh State University, Voronezh, Russia; tel.: +7 (473) 2208356, e-mail: tomina-e-v@yandex.ru

Boris V. Sladkopevtsev - Cand. Sci. (Chem.), Associate Professor of the Department of Materials Science and Industry of Nanosystems, Voronezh State University, Voronezh, Russia; tel.: +7 (905) 6505334, e-mail:dp-kmins@yandex.ru

Anna S. Parshina - Student of the Department of Materials Science and Industry of Nanosystems, Voronezh State University, Voronezh, Russia; tel.: +7 (473) 2208356, e-mail: anyuta_parshina@mail.ru

Dar'ya S. Balasheva - Student of the Department of Materials Science and Industry of Nanosystems, Voronezh State University, Voronezh, Russia; tel.: +7 (473) 2208356, e-mail: balasheva.98@mail.ru 